\title{
A METHODOLOGY FOR
} EVALUATION OF ALTERNATIVE TECHNOLOGIES APPLIED TO NUCLEAR FUEL REPROCESSING

Guna S. Selvaduray, Mark K. Goldstein, and Robert N. Anderson July 1977

\section{MASTER}

PREPARED FOR THE

NATIONAL SCIENCE FOUNDATION

UNDER GRANT NO. OEP-7519422

\section{DEPARTMENT OF APPLIED SCIENCE}

BROOKHAVEN NATIONAL LABORATORY ASSOCIATED UNIVERSITIES, INC.

UPTON, NEW YORK 11973 


\section{DISCLAIMER}

This report was prepared as an account of work sponsored by an agency of the United States Government. Neither the United States Government nor any agency Thereof, nor any of their employees, makes any warranty, express or implied, or assumes any legal liability or responsibility for the accuracy, completeness, or usefulness of any information, apparatus, product, or process disclosed, or represents that its use would not infringe privately owned rights. Reference herein to any specific commercial product, process, or service by trade name, trademark, manufacturer, or otherwise does not necessarily constitute or imply its endorsement, recommendation, or favoring by the United States Government or any agency thereof. The views and opinions of authors expressed herein do not necessarily state or reflect those of the United States Government or any agency thereof. 


\section{DISCLAIMER}

Portions of this document may be illegible in electronic image products. Images are produced from the best available original document. 
BNL 50700

(Chemical Separation Processes for

Plutonium and Uranium - TID-4500)

\section{A METHODOLOGY FOR \\ EVALUATION OF ALTERNATIVE TECHNOLOGIES \\ APPLIED TO NUCLEAR FUEL REPROCESSING}

Guna S. Selvaduray, 'Mark K. Goldstein, and Robert N. Anderson ${ }^{2}$

July 1977

RESEARCH SPONSORED

BY THE NATIONAL SCIENCE FOUNDATION

UNDER GRANT NO. OEP-7519422

IStanford University, Palo Alto, CA

${ }^{2}$ San Jose State, San Jose, $C A$ This report was prepared as an account of work
sponsored by the United States Government. Neither the United States nor the United States Department of Energy, nor any of their employees, nor any of their contractors, subcontractors, or their employees, makes any warranty, express of implied, or assumes any legal liability or responsibulity for the accuracy, completeness or usefulness of any information, apparatus, product or process disclosed, or represents that its use would not

DEPARTMENT OF APPLIED SCIENCE

BROOKHAVEN NATIONAL LABORATORY

UPTON, NEW YORK 11973 
IN OTIL:

(a) This material is based upon research supported by the National Science Foundation under Grant No. OEP-7519422:

(b) Any upiniuis, findlings, and conclusions or recommendations expressed in this publication are those of the author(s) and do not necessarily reflect the views of the National Science Foundation.

Printed in the United States of America

$$
\text { Availablc from }
$$

National Technical Information Service

U.S. Department of Commerce 5285 Port Royal Road Springfield, VA 22161

Price: Printed Copy $\$ 7.25$; Microfiche $\$ 3.00$

October 1977 400 copies 
An analytic methodology has been developed to compare the performance of various nuclear fuel reprocessing techniques for advanced fuel cycle applications including low proliferation risk systems. The need to identify and to compare those processes, which have the versatility to handle the variety of fuel types expected to be in use in the next century, is becoming increasingly imperative. This methodology allows processes in any stage of development to be compared and to assess the effect of changing external conditions on the process. 


\section{THIS PAGE}

\section{WAS INTENTIONALLY \\ LEFT BLANK}


Page No.

Abstract . . . . . . . . . . . . . . . . . . .

Table of Contents . . . . . . . . . . . . . . . . .

List of Tables ..................... . . . vi

List of Figures . . . . . . . . . . . . . . . . v vii

1. Introduction ..................... . . . . 1

2. The Requirement to Evaluate Reprocessing Techniques . . . . 6

3. The Evaluation Technique ............... 10

3.1 Performance Factor . . . . . . . . . . 10

3.1.1 Technical Complexity . . . . . . ...... 11

3.1.2 Safeguards of SNM ................ 12

3.1.3 Waste Volume .................. 17

3.1.4 Sensitivity to Changing Regulations . . . . . . . 18

3.1.5 Sensitivity to Change in Fuel Type . . . . . . . . . 19

3.1.6 Maintenance ................. 20

3.1.7 Development Factor . . . . . . . . . . . 20

3.1.8 Reliability .................. 21

3.1.9 Risk to Population . . . . . . . . . . . . . 21

3.1.10 Economic Advantages ............... 22

3.1.11 Decontamination Factor ........... 22

4. Results of Sample Analysis . . . . . . . . . . . 24

5. Application of this Analysis . . . . . . . . . . . 29

6. Conclusions . . . . . . . . . . . . . . 32

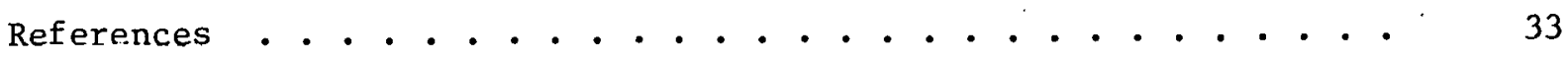

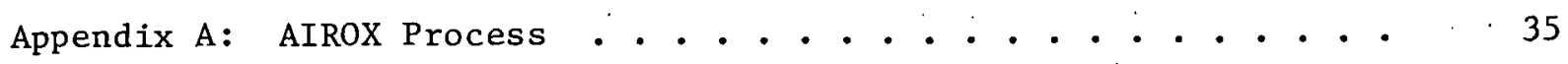

Appendix B: Electrochemical Salt Processing . . . . . . . . 41

Appendix C: Halide Volatility ............... . . 47

Appendix D: Hydride Process . . . . . . . . . . . . 53

Appendix E: Ion Exchange . . . . . . . . . . . . . 59

Appendix F: Photochemical Separation . . . . . . . . . . 65

Appendix G: Liquid-Liquid Partitioning . . . . . . . . . . 71 
$\therefore$

Appendix H: Melt Refining . . . . . . . . . . . . . . . . . . . .

Appendix I: Tin-Nitride Process . . . . . . . . . . . . . . . . .

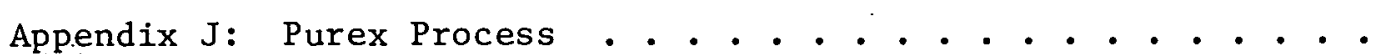

Appendix K: Redox Process . . . . . . . . . . . . . . . • . .

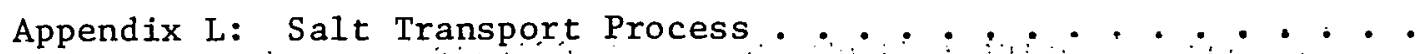

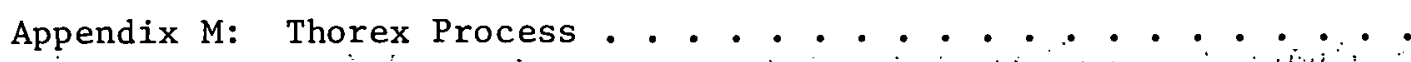

Appendix N: Zincal (Pyrozinc) • • • •

\section{LIST OF TABLES}

Page No.

Page No.

Table 1 List of 11 Subjective Descriptors ..........

Table 2 .18 Item Questionnaire 4

Talle 3 . List of Processes Selected for this Analysis....... 5

Table 4

Summary of Ratings of Performinces for the 14 Yroceesc3 ...................

Table 5

Summary of Cost Estimates ...........

Table 6

Fuel Types Accommodated hy the Reprocessing Techniques . . . . . . . . . . . . . . .

Table 7

Scenarios of Reprocessing Requiremento for Advallced fuel Cycle in 2020 . . . . . . . . . . . . 
Page No.

Figure $1 \quad \log _{10}$ Decontamination Factor . . . . . . . .

Figure 2 Flowsheet for On-Site Facility Based on the

AIROX Process..................

Figure 3 Proposed Fused Salt Electrolysis System of Reprocessing Involving a Dripping Manganese Cathode . . . .

Figure 4

Bromine Trifluoride Method, $\mathrm{BF}_{3}$ Regeneration and Uranium Purification . . . . . . . . . . .

Figure 5

Hydride Reprocessing Schemes as Visualized by the Authors . . . . . . . . . . . . . . .

Figure 6

Excer Process of Reprocessing in which Uranium in Fuels is Converted to Uranyl Nitrate Solution and is Separated from Alloying Element and Fission Products by Cation Exchange and Electrolytic Reduction and Precipitation . . . . . . . . . . . . . . . .

Figure 7 Photochemical Separation Scheme for Partitioning of of Reactor Waste Materials . . . . . . . . .

Figure $8 \quad$ Schematic Flowsheet for Magnesium Extraction of Plutonium from Molten Uranium . . . . . . . . .

Figure 9

Melt Refining Cycle . . . . . . . . . .

Figure 10 Tin-Nitride Process for Spent Fuel Reprocessing . .

Figure 11 Chemical Flow-Sheet for Treatment of Low Enriched

Uranium Fuel ................ 90

Figure $12 \quad$ Redox Flow Diagram . . . . . . . . . . . 98

Figure 13 Salt Transport Process . . . . . . . . . 106

Figure 14 Thorex Process and Materials Balance . . . . . . 112

Figure $15 \quad$ Zincal (Pyrozinc) Reprocessing Flow Diagram . . • . 118 


\section{1.. Introduction}

With the advent of President Carter's non-proliferation policy announcec on April 1977 there is a need to reevaluate various advanced nuclear reactor concepts, reactor fuels and reprocessing requirements. A number of methods for reprocessing spent nuclear fuels has been proposed. It is important that these processes be evaluated in light of the developing low proliferation risk systems that are currently being scrutenized, so that evaluation methods will be available to identify the most suitable spent fuel reprocessing techniques to facilitate commercial implementation of advanced fuel cycles.

Of the various techniques suggested for the reprocessing of spent nuclear fuel, the one based on solvent extraction is probably the best known, most developed and most widely employed. Other techniques include electrochemical, halide volatility, pyrometallurgical, and photochemical separation among others. Without a formal decision analysis methodology it would be difficult to select a superior technique for a given situation. The comparative evaluation and selection is further complicated by the fact that all of the above processes are at different stages of development. Therefore a clearly superior technique, currently in the conceptual stage, might be rejected in favor of a more developed, but inferior technique. To this complexity can be added such factors as changing fuel types, safety regulations, economics and the world political pressures .

Though the primary aim of any reprocessing technique is the separation of reusable fuel from the poisonous fission products, a comparison of the various techniques should not be based on this one consideration, alone.

Other critical factors, including economics, environmental impact, safeguards of Strategic Nuclear Materials (SNM), acceptability to government and 
local regulations, adaptability to changes in fuel type, must be included to provide a valid meaningful comparison. However, it must be noted that the various factors, while important, are not of equal significance. These factors must be weighted according to their importance and contribution. The particular weight assigned to a factor will also depend upon the prevailing conditions at a given time. Also variations in weight will exist as a reflection of the emphasis that a particular individual wishes to place on the analysis. The methodology allows the user the flexibility of analyzing a vartety of weighted pol.icy scenarios rapidly and simply.

In order to accommodate all of these variables, an analytical technique employing 11 subjective parameters (1isted in Table 1) was developed. These parameters are assigned a 1 to 10 rating depending upon results of an objective 18-item questionnaire 2 (listed in Table 2). By assigning a ranking factor to each parameter, the analysis provides: a numerical measure of performance for each process. As an illustration of this methodology of the 32 reviewed $^{1}$ fourteen processes selected are listed in Table 3. 
1. Téchnical Cómplexity.

2. Safeguards of Strategic Nuclear Materials (SNM)

3. Magnitude of Waste Problems

4. Sensitivity to Changing Safety Regulations

5. Sensitivity to Change in Fuel Type

6. Maintenance Problems

7. Development Factor

8. Reliability

9. Risk to Population

10. Economic Advantage

11. Decontamination Factor 


\section{Table 2: 18-Item Questionnaire}

1. Unit cost of production for each unit operation at 1 ton/day

2. Estimated capital cost of plant

3. Separation factor for fission products

4. Fission product waste form

5. Waste material produced per kilogram of fuel reprocessed

6. Waste radiation level

7. Fuel type accommodated

8. Fucl cooling iéquilemenls

9. Breeder fuel capability

10. Batch or continuous process

11. Handling of cladding material

12. Form of reprocessed material

13. Plutonium handling

14. Handling of radioactive gases

15. Throughpur/process inventory

16. Maximum credible accident

17. Advantages

18. Disadvantages 
Table 3: List of Processes Selected for This Analysis

\begin{tabular}{lcc}
\hline Process & $\begin{array}{c}\text { Reference } \\
\text { Number }\end{array}$ & $\begin{array}{c}\text { Appendix } \\
\text { No. }\end{array}$ \\
\hline 1. Airox & 1 & $\mathrm{~A}$ \\
2. Electrochemical & 2 & $\mathrm{~B}$ \\
3. Halide Volatility & 3 & $\mathrm{C}$ \\
4. Hydride & 4 & $\mathrm{D}$ \\
5. Ion-Exchange & 5 & $\mathrm{E}$ \\
6. Photochemical & 6 & $\mathrm{~F}$ \\
7. Liquid-Liquid & 7 & $\mathrm{G}$ \\
8. Melt Refining & 8,9 & $\mathrm{H}$ \\
9. Tin-Nitride & 10 & $\mathrm{I}$ \\
10. Purex & 11 & $\mathrm{~J}$ \\
11. Redox & 12 & $\mathrm{~K}$ \\
12. Salt Transport & 13 & $\mathrm{~L}$ \\
13. Thorex & 15 & $\mathrm{~N}$ \\
14. Zincal (Pyrozinc) & &
\end{tabular}




\section{The Requirement to Evaluate Reprocessing Techniques}

The aqueous solvent extraction reprocessing methods all have a common principle of separation. The other reprocessing methods, selected for this sample analysis, are based upon different principles of separation which we feel illustrates the methodology adequately without having to consider all available techniques. The halide volatility process is based upon the difference in vapor pressure of the halides of uranium, plutonium and the fission products, at a given temperature. Electrochemical separation is based upon the difference in activity in solution, and hence the difference in electromotive force required to selectively drive the fission product to one of the electrodes. Pyrometallurgical and other techniques are based on various other principles of separation. In all cases, the starting point and the end point do not differ; what differs is the route taken. The various factors having " effects on this route are constantly changing, and the sensitivity of each route to changing conditions needs to be established.

However, before the fuel reprocessing technique itself can be considered, the constraints that apply to the input material must be examined. For example, the spent fuel will be in claddings and will have a finite radioactivity level. Processes which cannot simultaneously process the fuel and the cladding material will require that the cladding be separated from the tuel betore reprocessing. Processes which utilize media susceptible to radiation damage will require the fuel be cooled to an acceptable activity prior to reprocessing. The former constraint means head-end treatment facilities will be required. The latter constraint will determine the necessity for and the length of storage for precooling. 
A further constraint on the input material is its chemfcal form. Nuclear fuels could come in many forms - metallic, oxides, carbides, nitrides, and alloys. A process designed to handle all materials as oxides might or might not be converted easily to process a chemically different form of fuel. The ease of conversion will depend upon the chemistry and thermodynamics of the process. If the process is limited to handling the spent fuel in only one form, for example, in the oxide form, then, non-oxide fuels would either have to be converted to oxides before being reprocessed, or an alternative process would be required.

The physical form of the fuel adds a further complication. Techniques which require dissolution of the input before separation will be able to handle metallic fuels with greater ease than carbon-coated pellets. The carbon coating would have to be removed by some means, prior to separation. The dissolum tion of fuels with a carbon coating could result in the formation of the carbides, thus rendering it unsuitable to separation by liquid metal techniques; or, the solubility of carbon in the solvent might have adverse effects on the solubility and subsequent reaction of the fuel.

A significant aspect of reprocessing spent nuclear fuels is associated with waste disposal. The nature and quantity of the wastes produced has to be considered. A waste disposal method which merely transforms the waste to another form of waste would be self-defeating; such a method would not solve the problem of separating the wastes in a disposable form.

Factors affecting the economics are multifarious. A highly efficient process requiring less plant equipment will probably require less capital and lower operating expenses compared to another process having a lower efficiency and requiring more plant equipment. Two factors which have a great influence on process economics are: 
1. the fuel pre-cooling requirements; and

2. the location of the reprocessing plant, i.e., on-site or off-site.

A reprocessing method requiring fuel pre-cooling immediately incurs two expense items: capital expenditure for spent fuel storage and higher fuel inventory costs. Reprocessing plant location is basically a trade-off between transportation costs and processing costs. To minimize processing costs, any processing plant should operate at, or close to, $100 \%$ of capacity. As the facility utilization decreases, the cost of reprocessing per unit increases.

One possibility is to have one reprocessing plant service a single reactor thereby eliminating the cost and hazards of transportation. Such an operation would probably be on a relatively smaller scale and the reprocessing plant might not run at $100 \%$ of design capacity.

On the other hand, it would also be possible to build larger centrally located, reprocessing plants which would have lower per kilogram of throughput processing costs. The penalty of transportation costs and hazards would have to be considered. Such a choice would naturally be influenced by the number, capacity and location of the nuclear reactors to be serviced as well as the proliferation risks.

In essence, what is needed is a method of analysis which will not just indicate which process is most technically suited for the reprocessing of spent fuel from advanced nuclear reactors, but more important1y, the method should enable us to make integrated decisions via properly formulated guidelines.

In order to execute such a comprehensive analysis, the pertinent factors have to be identified, and the effect these factors will have on the system as a whole determined. With that objective in mind, the methodology described 
in the following section has been developed. It should be emphasized that in the analysis presented the weighted policy parameters have been chosen to illustrate the methodology, not to set policy for reprocessing decision makers. Quantifying these policy parameters will have to be determined by more a detailed study, which is currently in preparation. ${ }^{2}$ 
3. The Evaluation Technique

In comparing any two processes due consideration has to be given to all related factors. An economic analysis will be meaningful for the specific purpose of studying economic considerations; but to attempt to establish superiority of one process over another based purely on an economic analysis will be meaningless. The same can be said for any such comparative attempt based on just one or two criteria.

To make a meaningful comparison, not only must the relevant factors be identifled, but the impact of these factors in the comparison must be established. The "Impact" consideration is called "ranking" in this report. The different factors need to be ranked according to their degree of importance in the analysis. The ranks assigned will invariably depend on the analyst; however, by virtue of having established a ranking, the direction of emphasis (or the bias) of the analyst will be evident. The ranking chosen herein is for illustrative purposes only, and is not meant to be absolute.

The superiority of the technique developed here lies in the fact that while permitting emphasis in any chosen direction, it simultaneously compels the analyst to take into account, though to a lesser degree, other pertinent factors. In essence, a one-criterion comparison is avoided.

The purpose of this analysis is to establish a method by which various spent fuel reprocessing techniques can be evaluated for their application to low proliferation risk fuel cycles or other advanced fuel cycles.

\subsection{Performance Factor}

The 18-point questionnaire shown in Table 2 was formulated to record the performance and ability of each process in an efficient and easily compared manner. Based on this data, the 11 subjective descriptors listed in Table 1 
were assigned a 1 to 10 rating. The rating for each descriptor is multiplied by a ranking factor which assigns the desired importance to be given to this descriptor. The product of the rating, " $r$ ", and the ranking "R", gives the total value for the item. The sum of the product, rR, for all descriptors, divided by the maximum potentlal value which is equal to $10 \Sigma \mathrm{R}$, gives the numerical Performance Factor, "e", for the process as shown by the equation:

$$
\mathrm{e}=\frac{\sum \mathrm{rR}}{10 \Sigma \mathrm{R}}
$$

The questionnaire in Table 2 outlines the factors to be considered about the various processes, but does not answer the critical questions involved in decision making. The critical questions are the subjective descriptors listed in Table 1. Though these descriptors are not directly quantiflable, the knowledge gained from Table 2 provides the necessary information to assess the ratings. Needless to say, these ratings will also be on a comparative basis, depending on the nature of the descriptor.

\subsubsection{Technical Complexity}

In general, the overall complexity of a process can be equated to the complexity of the principle employed to achieve the goal: This appears in terms of increased number of unit operations, more stages in each operation, a greater need of safeguards to assure the degree of achievement, more precise control equipment, sophisticated labor requirement's, and greater capital investment. One criterion used to assess the technical complexity of the processes being evaluated in this report is the principle of separation employed. The various methods have been divided into absolute and relative separation techniques. An absolute separation technique, (for example, a sink-float separation based on 
differences of densities) will separate two materials of differing densities in one stage. Another technique, based on differences in relative solubilities, might achieve $90 \%$ separation in the first stage, $99 \%$ in the second stage, and so on, with $100 \%$ separation being theoretically achieved by an infinite number of stages.

Therefore, if a relative principle of separation is used, a cut-off point will have to be established; then, the number of stages to achieve this degree of separation will have to be determined. As the number of stages increase, the contents of the valuable material will decrease, and the control equipment required will have to be of greater precision. An increase in the quantity and quality of equipment invariably links with increased capital expenditure. Absolute separation techniques may have some inherent contamination. If this level of contamination is above the permissible level, then further refining equipment will be required.

In addition to the above process complexities, all processes which require remote refabrication of the fuel rods have been penalized, as this arditinnat requirement increases the technical complexity of the tail-end of the Fuel Cycle. Details of quantization are given by Selvaduray. ${ }^{2}$

\subsubsection{Safeguards of Strategic Nuclear Materials}

Strategic nuclear materials (SNM) consist of some fissile materials from which weapons can be made, namely ${ }^{233} \mathrm{U},{ }^{235} \mathrm{U}$, and $\mathrm{Pu}$, and have been defined as follows by the Nuclear Regulatory Commission:

$$
\text { i. } 2 \mathrm{~kg} \text {. of } \mathrm{Pu} \text { or }{ }^{233} \mathrm{U} \text {; }
$$

ii. $5 \mathrm{~kg}$. of uranium enriched to more than $20 \%$ in ${ }^{235} \mathrm{U}$;

1ii. a combination of these materials. 
These quantities are established at a level substantially below that required for the manufacture of nuclear explosives.

Other actinides can be used to construct weapons, e.g., neptunium, and should be considered as SNM. Once reprocessing has become common world wide, tons of neptunium and other actinides could be diverted for weapon construction if overlooked by international safeguards.'

Safeguards of strategic nuclear materials can be thought of on two levels:

i. International Nuclear Proliferation or horizontal proliferation; and

ii. Diversion of weapons grade material by subnational groups.

International nuclear proliferation is the increase in the number of countries that are capable of manufacturing a nuclear explosive. Implicit in this concept is the fact that the weapons grade material can be clandestinely or openly produced.

of the strategic nuclear materials, ${ }^{235} \mathrm{U}$ can be obtained only by the arduous task of isotope enrichment via either gaseous diffusion or centrifuging. (The advent of laser isotope enrichment could possibly simplify this task greatly.) The technology is extremely sophisticated, the capital expenditure very high, and as a result is not within the reach of most nations at this time. The other weapons materials, ${ }^{233} \mathrm{U}$ and $\mathrm{Pu}$ are bred (or converted) in nuclear power reactors. The fertile ${ }^{232} \mathrm{Th}$ is chemically different from the fissile ${ }^{233} \mathrm{U}$; 1ikewise with ${ }^{238} \mathrm{U}$ and $\mathrm{Pu} .{ }^{233} \mathrm{U}$ and $\mathrm{Pu}$ can be separated chemically from ${ }^{232}$ Th and ${ }^{238} \mathrm{U}$ respectively, by processing (or reprocessing) the spent nuclear fuel. However, spent nuclear fuel also contains fission products, several of which are neutron poisons (absorbs neutrons without fissioning). Materials containing ${ }^{233} \mathrm{U},{ }^{235} \mathrm{U}$, and $\mathrm{Pu}$ can be used for making fission explosives only if these isotopes are sufficiently concentrated. For each iso- 
tope, a minimum concentration in ${ }^{238} \mathrm{u}$ can be specified below which the mixture is not usable in a practical nuclear explosive. For ${ }^{235} \mathrm{U}$ this concentration is $20 \%$. This will be a bare sphere critical mass of metal containing $20 \%{ }^{235} \mathrm{U}$ and $80 \%{ }^{238} \mathrm{U}$, and weighing about $850 \mathrm{~kg}$. The critical mass can be reduced by a fac-

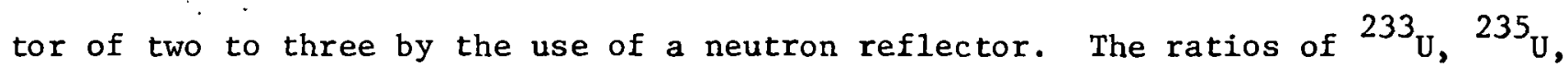
${ }^{239} \mathrm{U},{ }^{239} \mathrm{Pu}$ and reactor-grade $\mathrm{Pu}$ to ${ }^{238} \mathrm{U}$, corresponding to a critical mass of about $850 \mathrm{~kg}$. are $1: 8,1: 5,1: 8$, and $1: 7$ respectively.

In fitting the spent nuclear fuel reprocessing industry into the international proliferation scenario, it is evident that reprocessing techniques that do not separate the fissile from the fertile materials, and at the same time having low decontamination factors, run a lower risk of making available weapons grade SNM.

Safeguarding of strategic nuclear materials from subnational groups basically involves the guarding of the sources of these materials. The basic elements of this aspect of safeguards are surveillance, containment or physical protection, and material balance accounting. Containment can involve the use of fences, substantial walls and enclosures, locks, tags, seals and similar measures. Surveillance" includes direct observation and monitoring, and verification of plant operation and plant data. Material balance accounting is concerned with records, reports, and source data from the facility being inspected, and independent measurement as needed to form independent conclusions on materials accountability. While surveillance and physical measures provide direct and timely information on safeguarded material, accounting procedures provide indirect or circumstantial evidence.

The unauthorized movement of SNM from protected areas can take place by two means: it can either be stolen by force, or diverted by people having ac- 
cess to it. However, for the material to be stolen or diverted, it would have to be in a form that is desirable from the point of view of the potential saboteur. In terms of "desirability," isolated plutonium without any diluents and in a form readily convertible to metal will probably be the most desirable. With increasing contamination the desirability decreases, since the thief will have need of sophisticated refining know-how and special equipment. Moreover, the fission-product contaminants make it easier to trace the plutonium.

The easiest point of diversion of SNM is probably during transportation. Transportation can be one of four modes: ship, train, airplane, or truck. Past hijacking incidents have shown that airplanes and trucks are predominantly the subjects of potential hijackers. This can be attributed to the fact that both airplanes and trucks can be relatively easily diverted to the hijackers desired destination once he/she has gained control over the vehicle. Trains on the other hand, can travel only on rails. Though the opportunities to hijack a train may be more abundant, the difficulty of transporting the required materials to the desired destination does seem to be a deterrent. Ships travel so slowly that even if hijacked, can be quite easily blocked. Furthermore, if they can be sufficiently separated from areas of population, any threatened damage will be of little, if any, consequence. Hence, it is felt that it can be concluded that the likelihood of a hijacker hijacking a ship or train are small, while airplanes and trucks run a much larger likelihood of being hijacked.

Reprocessing methods suitable for operation on a small scale, i.e., those which are suitable for the reprocessing of spent fuel from just one reactor, will have no long-distance transportation requirements. Both reactor and fuel reprocessing plant can be contained within one security system, and any material leaving the premises can more easily be identified. On the other hand, methods 
which are suitable for large scale operation, or those that benefit greatly from economy of scale will probably be centrally located so that a number of nuclear reactors can be serviced. Short of the establishment of nuclear parks, such a system will, of course, have transportation needs, and will increase the potential for theft.

The factors affecting the safeguards issue can be redivided into two categories:

i. Those which are a function of the prosess; and

ii. Those which are a function of implementation and policy.

It is the first of these two categorles that is of most concern in this analysis. The following factors can be identified as being either a function of the process, or being closely related to it:

i. Separation of fissile material from fertile materials - i.e., is plutonium produced as an independent stream, or is the process aimed at plutonium separation only?;

ii. Decontamination Factor;

111. Suitable tor on-site operation or off-site operation sprvicing two or more reactors;

iv. Labor intensity of the process;

v. Materials accountability - this is rclated to the process in the sense that processes with fewer effluent streams will afford better materials accountability as opposed to processes with several effluent streams,

If plutonium does exist, then it has to be available for diversion; offsite transportation greatly facilitates this - especially in the case of international proliferation. Once the material comes off-site and is available for diversion, its "desirability" can be directly correlated to its purity. 
Labor intensity and materials accountability (interpreted in terms of number of effluent streams) are also factors that could facilitate diversion. The larger the working force, the larger the number of people having access to restricted areas, or "legal" entrance into the area in which the facility is situated. This increases the risk of an "inside job" being planned.

Materials accountability should be good in a reprocessing plant, since this can be a crucial factor in the discovery of the occurrence of a diversion. If there exists several streams carrying plutonium, then a group could enter a plant, drain off one of these lines, and leave undetected with a significant quantity of SNM. They could alternately accumulate the material over a span of time, operating within the limits of error of these several streams. On the other hand, if there is just one stream, the lack of any material can be detected in the next process step, thus leading to early detection of the loss.

However, these later two factors have been considered on lower level of concern because the role they play is one of facilitating the diversion, rather than actual participation in the act of diverting.

\subsubsection{Waste Volume}

Waste from a reprocessing plant can be evaluated in terms of volume, form (gas, liquid or solid), activity levels, and toxicity. Three of the important radioactive waste gases are iodine, krypton, and xenon. These are liberated when the fuel element is dissolved or heated. It can be safely assumed that all the reprocessing methods considered here produce approximately the same amount of waste gases.

For processes utilizing aqueous solutions, liquid wastes constitute the major aspect of the disposal problem. From the standpoint of disposal, liquid wastes can be divided into two broad categories: (a) "high-level" wastes with 
activities in the range of curies per liter, and (b) "low-level" wastes with activities in the microcurie per liter range. High-level radioactive wastes from fuel reprocessing plants in the past have been stored in underground tanks. Low level wastes are in the best situation concentrated or stored in barrels.

Processes employing liquid metals will produce solid wastes. In addition, filters, absorption materials, and discarded process equipment from any reprocessing method constitute solid wastes.

Based upon the assumption that all wastes produced will be stored it is evident that reliability of storage facilities are best for solid wastes. Liquid and gaseous wastes contain within them the inherent ability to disperse when released from containers. The potential danger from escaped wastes is directly proportional to radioactivity levels and the chemical form of the material as well as its surroundings. Hence, in terms of ease of handling, convenient storage and over-all safety, low volume low activity, solid wastes are quite manageable. Large volume-high activity liquid and gaseous wastes are less manageable. These parameters have been quantified based on the ahnve rriteria. 2

\subsubsection{Sensitivity to Changing Regulations}

Development in the nuclear industry has been so fast that, generally, regulations are lagging behind. Federal and local regulatory bodies are constantly developing more stringent safety requirements. Many of the more recent regulations have been enacted long after plants have been built, resulting in increased capital equipment costs.

It is extremely difficult to foresee the types of regulations that might be enacted in the future. However, it is believed that regulations regarding 
safety, waste disposal, and extraction and isolation of the fission products are the areas that will have a large impact on fuel reprocessing facilities. Sensitivity of reprocessing methods to changing regulations has been judged on the above criteria. ${ }^{2}$

\subsubsection{Sensitivity to Change in Fuel Type}

Fuel specifications for nuclear reactors are continually changing. In addition to metallic uranium, the oxides, carbides, nitrides, as well as alloyed fuels are being used. Further, some of these fuels are in the form of coated particles.

Uranium metals are being used in low exposure natural uranium systems. For water-cooled reactors, the presently favoured and most thoroughly proven fuel material is uranium oxide. Carbide fuels appear promising for non-water reactors. Studies of other fuel compounds such as nitrides, sulfides, and silicides are also progressing. For future applications, ceramic fuel particles coated with carbon (or other material) offer an interesting fuel for hightemperature gas cooled reactors. A number of fluid concepts, utilizing molten salt, gaseous core, molten plutonium and aqueous slurries, have been studied. Fast breeder reactors using the plutonium and U-238 or thorium and U-233 fuel cycle, or a combination of these such as the denature thorium cycle, and thermal breeders fueled on thorium and U-233 are very atractive as they promise to extend, by an order of magnitude or more, the fuel utilization of our uranium and thorium resources.

The ideal reprocessing technique should be able to reprocess any fuel type that is fed into it. Such adaptability will naturally depend upon the chemistry. and thermodynamics of the process. Some of the processes have been developed 
for one specific fuel type and the risk of adopting such a process for further development needs no emphasis.

Processes believed to be able to handle any conceivable fuel type (i.e., 8 or more) were given a rating of 10. Processes capable of handling only one type of fuel receive a rating of 3 ; the intermediate levels are prorated. ${ }^{2}$

\subsubsection{Maintenance}

An important factor for a successful process is trouble-free operation. Likely operational troubles and maintenance requirements will depend on the materials used in the process and the materials used in the equipment. Equipment that is remotely controlled might have a breakdown once a ycar; however, if the corrective maintenance required that the whole plant to be shut down, and, in addition, required highly skilled labor to effect the repair, the economic significance might make that system unattractive. For comparison, stainless steel tanks require regular maintenance; however, that work can be done relatively easily and without plant shut-down. An attempt has hepn made to 2ssess the dollar-value of the maintenance work required and quantify the parameter associated with the maintenance. ${ }^{2}$

\subsubsection{Development Factor}

The commercial availability of a process is directly dependent on the level to which it has been developed. Therefore, processes that have been operated on a commercial scale have been rated 10; processes that have been developed to the pilot plant stage have been rated 8 or 9; techniques that have been studied on a laboratory scale from 3 to 7 , depending upon the quantity and quality of the study; and reprocessing methods that are in the conceptual stage, a rating or 1.2 
The inclusion of the development factor is important in this analysis as it focuses attention on the processes which might otherwise be dismissed as not feasible for the simple reason that insufficient effort has gone into proving their worth.

\subsubsection{Reliability}

Reliability has been assessed in terms of the ease with which the process attains the final objective, and in addition, the vulnerability to changing and/or fluctuating conditions. Therefore, methods requiring multistage separation will be less reliable than a single stage separation. The uncertainties in each stage are multiplicative. ${ }^{2}$

Techniques utilizing reagents, solvents, and/or equipment sensitive to radiation will not tolerate large fluctuation in activity levels. Any error in quality control on the input could easily have adverse effects on the process, enlarging the quality of the end product as well as safeguards, e.g., the limit of error of material unaccounted for (LEMUF).

\subsubsection{Risk to Population}

Each process has been evaluated for the potential danger it might pose to the nearby population in the event of a natural calamity (such as an earthquake), or man-inspired damage (i.e., sabotage). A main objective is to prevent the ease of dispersion of the nuclear products. Aqueous liquids when spilled, will flow to lower levels. If they come into contact with ground water or streams, they will then be carried. further. Even in stagnant pools, liquid diffusion is quite fast. On the other hand, liquid metals, and salts, when spilled, will cool and solidify, naturally preventing dispersion. Winds will only enhance the cooling of these high temperature liquids. Therefore, processes employing large volumes of aqueous liquids pose the greatest poten- 
tial danger; whereas, processes which will automatically contain themselves, in the event of a calamity are least hazardous. ${ }^{2}$ The probability of design failure and process effluents are other parameters that need to be accounted for in a more detailed analysis. ${ }^{2}$

\subsubsection{Economic Advantage}

In assessing the economic advantage of the various processes, the cost of processing 1 kilogram of fuel per day, was estimated. These cost estimates were based on flow sheets which indicate only blocks of equipment, and not on detailed engineering designs. In cases where more detailed information was available, the information was incorporated into the estimates, and the costs updated to 1975 dollars using the Marshall and Stevens Equipment Cost Index and Chemical Engineering Plant Cost Index. It must be reiterated that processing costs only have been estimated; other costs, such as head-end treatment, fuel transportation, inventory, safeguards and safety requirements, as well as $\mathrm{R} \& \mathrm{D}$ have not been included. The inclusion of such factors would, of course, affect the over-all costs. However, from the standpoint of illustrating the methodology presented in this paper these costs esrimares are adequate.

The process with the lowest cost of reprocessing was given a rating of 10, that with the highest a rating of $1 .^{2}$ The processes in between, have been assigned ratings by linear interpolation. ${ }^{2}$

\subsubsection{Decontamination Factor}

Decontamination of the recycled fuel is necessary for a preservation of neutron economy in the reactor. Higher decontamination factors are desirable. To meet neutron economy requirements, a decontamination factor of at least $10^{2}$ should be achieved. This has been assigned a rating of 1 . Decontamination 
factors of $10^{6}$ and above have been rated 10; the interval being prorated on a logarithmic scale. ${ }^{2}$

There is another concept called co-processing which could reverse these ratings, i.e., the co-processing concept assumes the least decontamination required the better since diversion of sum would be less likely. This concept would have advantages from a safeguards view point but would suffer economically because of remote fuel fabrication requirements. ${ }^{1}$ 


\section{Results of Analysis}

The results of this sample analysis are shown summarized in Table 4. The Performance Factor shown in this Table is that calculated according to Equation (1) multiplied by 100 for convenience.

The ranking of these 11 parameters represent the subjective decision of the authors made primarily to illustrate the utility of the methodology. A survey has been made to determine the general ranking importance assigned to these parameters by the technical community, government agencies, utilities and the public. ${ }^{2}$

The IIn-Nicride high temperature Process has the highest performance factor and the Ion Exchange Process has the lowest performance factor based on the authors ranking (a complete analysis using this new methodology is in prepara$\left.\operatorname{tion}^{2}\right)$.

It is unfortunate that more than half of the processes investigated have not been developed to the pilot plant stage. Hence, the data available is from limited laboratory experiments. The development of pilot plants will establish both the advantages and limitations more vividly. This type of analysis could prove useful in identifying those separation processes most promising for further development.

A summary of the cost of reprocessing spent fuel by the 14 processes is given in Table 5. The last column shows the cost factor compared to Purex which was taken as the base. A summary of the fuel type accommodated by earh reprocessing method is compiled in Table 6 . While the decontamination factors of the various processes are depicted in Figure 1. 


\section{Table 4: Summary of Ratings \& Performance Factors for the 14 Processes}

Process

Descriptor

1. Technical Complexity

2. Safeguards of Plutonium

3. Magnitude of Waste Problem

4. Sensitivity to Changing Safety Regulations

5. Sensitivity to Change in Fuel Type

6. Maintenance Problems

7. Development Factor

8. Rellability

9. Risk to Population

10. Economic Advantage

11. Decontamination Factor

TOTAL

PERFORMANCE FACTOR

\begin{tabular}{|c|c|c|c|c|c|c|c|c|c|c|c|c|c|}
\hline 若 & 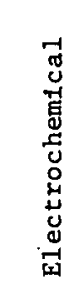 & 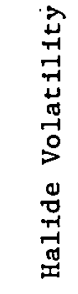 & 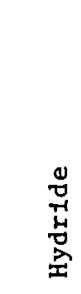 & 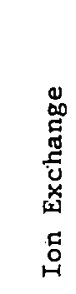 & 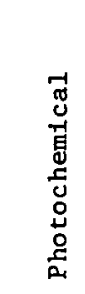 & 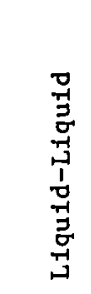 & 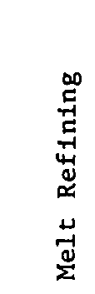 & 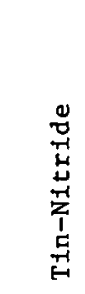 & 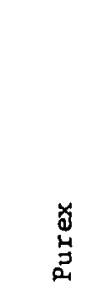 & $\begin{array}{l}\text { ox } \\
\text { ợ } \\
\text { ơ }\end{array}$ & 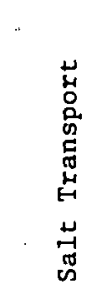 & 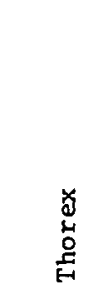 & 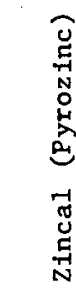 \\
\hline 8 & 5 & 4 & 3 & 4 & 4 & 7 & 9 & 8 & 3 & 3 & 4 & 3 & 6 \\
\hline 9 & 8 & 5 & 7 & 3 & 3 & 8 & 8 & 8 & 5 & 5 & 5 & 5 & 8 \\
\hline 9 & 8 & 4 & 9 & 3 & 4 & 8 & 9 & 9 & 3 & 3 & 6 & 3 & 9 \\
\hline 3 & 7 & 6 & 3 & 4 & 4 & 5 & 5 & 5 & 4 & 4 & 7 & 4 & 5 \\
\hline 3 & 3 & 8 & 3 & 4 & 10 & 7 & 3 & 7 & 4 & 4 & 8 & 4 & 3 \\
\hline 8 & 4 & 6 & 5 & 5 & 3 & 5 & 5 & 5 & 8 & 8 & 6 & 8 & 5 \\
\hline 4 & 3 & 9 & 3 & 9 & 1 & 3 & 9 & 4 & 10 & 9. & 8 & 10 & 3 \\
\hline 4. & 7 & 8 & 2 & 8 & 6 & 5 & 7 & 8 & 9 & 9 & 7 & 9 & 6 \\
\hline 7 & 8 & 3 & 7 & 4 & 5 & 9 & 9 & 9 & 4 & 4 & 6 & 4 & 9 \\
\hline 6 & 10 & 8 & 9 & 5 & 9 & 10 & 8 & 10 & 3 & 1 & 9 & 4 & 10 \\
\hline 1 & 2 & 10 & 2 & 3 & 10 & 4 & 1 & 4 & 10 & 10 & 10 & 10 & 2 \\
\hline 473 & $483^{\circ}$ & 464 & 390 & 366 & 393 & 515 & 536 & 564 & 434 & 420 & 506 & 439 & 506 \\
\hline 61 & 63 & 60 & 51 & 48 & 51 & 67 & 70 & 73 & 56 & 55 & 66 & 57 & 66 \\
\hline
\end{tabular}


Table 5: Summary of Cost Estimates (All Costs in 1975 U.S. \$)

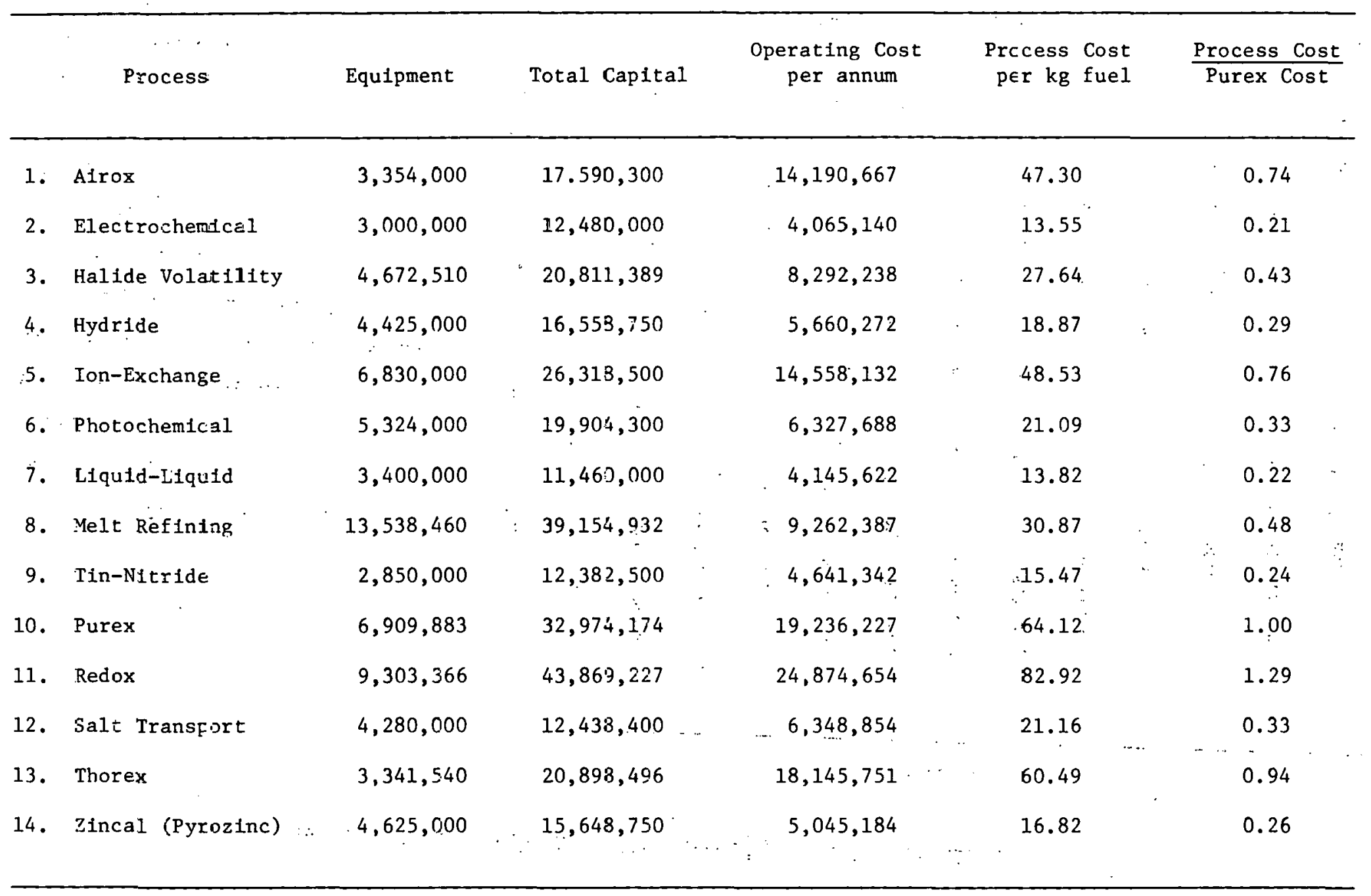


Table 6: Fuel Types Accommodated by the Reprocessing Techniques

\begin{tabular}{|c|c|c|c|c|c|c|c|c|c|c|c|}
\hline \multirow{2}{*}{\multicolumn{3}{|c|}{ Process }} & \multicolumn{8}{|c|}{ Fuel Type } & \multirow{3}{*}{ Remarks } \\
\hline & & & $\overline{\mathrm{U}}$ & $\mathrm{UO}_{2}$ & $\mathrm{UC}$ & & Alloy & $\mathrm{Pu}$ & Th & $\mathrm{ThO}_{2}$ & \\
\hline & & : & & & & & & & & & \\
\hline 1. & Airox & & & $\mathrm{X}$ & & & & & & & \\
\hline 2 . & Electrochemica & & $x$ & & & & & $\mathrm{X}$ & $\mathrm{X}$ & & . \\
\hline 3. & $\begin{array}{c}\vdots \\
\text { Halide Volatil }\end{array}$ & lity & $\mathrm{X}$ & $\mathrm{X}$ & & & $x$ & $\mathrm{X}$ & $\mathrm{X}$ & $\mathrm{X}$ & Possibly UC \\
\hline 4. & Hydride & $\vdots$ & $x$ & & & & . & & & & \\
\hline 5 . & Ion-Exchange & : & $\mathrm{X}$ & $\mathrm{X}$ & & & & $\mathrm{X}$ & $\mathrm{X}$ & $\mathrm{X}$ & Soluble in $\mathrm{HNO}_{3}$ \\
\hline 6. & 'Photochemical & $\vdots$ & $\mathrm{x}$ & $\mathrm{X}$ & $\mathrm{X}$ & , & $\mathrm{X}$ & $\mathrm{X}$ & $\mathrm{X}$ & $\mathrm{X}$. & \\
\hline 7. & $\underset{;}{\text { Liquid-Liquid }}$ & : & $\mathrm{x}$ & & 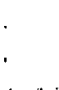 & $\vdots$ & . & $\mathrm{X}$ & $\mathrm{X}$ & & . \\
\hline 8. & Melt Refining & . & $\mathrm{X}$ & & . & & $\therefore$ & - & . & & \\
\hline 9. & Tin-Nitride & $\therefore$ & $X$ & $\mathrm{x}$ & $\mathrm{x}$ & : & $\mathrm{X}$. & & & ; & $\therefore$ \\
\hline 10 . & Purex & & $\mathrm{X}$ & $\mathrm{X}$ & . & $\therefore$ & . & $\mathrm{x}$. & & & Soluble in $\mathrm{HNO}_{3}$ \\
\hline 12. & Salt Transport & & $\mathrm{x}$ & $\mathrm{X}$ & $\therefore \mathrm{x}$ & $\because$ & $\mathrm{X}:$ & $\mathrm{x}^{2}$ & $\mathrm{X}$ & . & \\
\hline 13. & Thorex & & & & & & & $\mathrm{x}$ & $\mathrm{X}$ & & Soluble in $\mathrm{HNO}_{3}$ \\
\hline 14. & Zincal & . & $\mathrm{X}$. & $\mathrm{x}$ & . & $\therefore$ : & $\therefore$ & & : & & Possibly UC \\
\hline
\end{tabular}




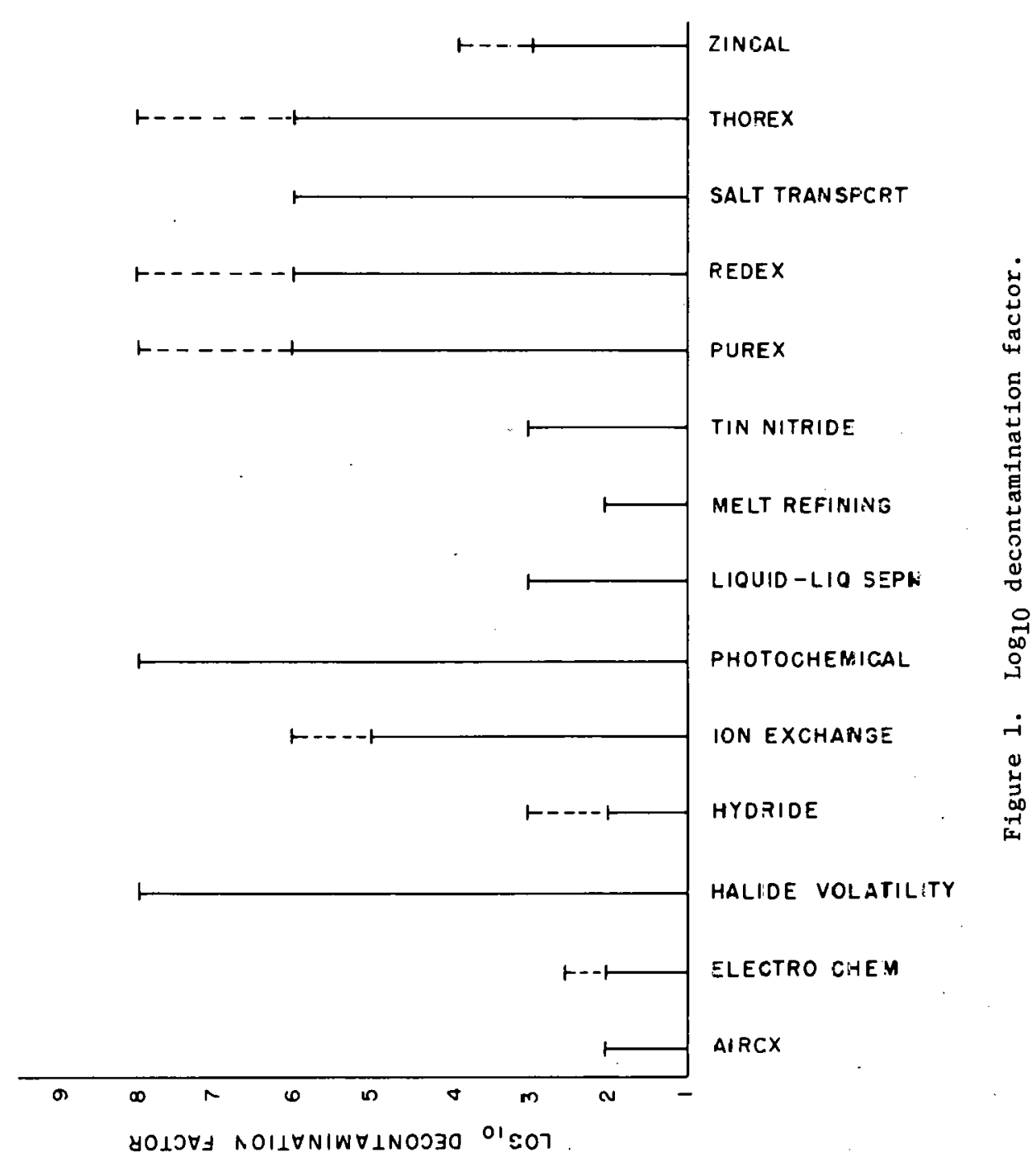


5. Application of this Analysis to Low Proliferation Risk and Advanced Fuel Cycles

A continuing review of the advantages and disadvantages of various reprocessing methods for advanced fuel cycles is required because the relative position of these techniques will change as new technical developments occur in materials and processing and as new perception of risks become factored into policy decision analysis. This methodology is capable of characterizing and quantifying the advantages and disadvantages of alternative fuel cycles. This analysis can be performed as a function of a chosen mix of reactor fuel types employed to meet a variety of future energy demands.

An example of its application is shown in the following scenario presented in Table 7. This is based on an assumed fuel mix in 2020. The results show the required processing for the constraints given in Notes 1 and 2 . This scenario is not intended to be a forcast, but was chosen strictly to illustrate the usefulness of this methodology in planning and analysis exercises. 
Tatile 7: 3cerarios of Reprocessing Requirements for Advanced Fuel Cycle in 2020

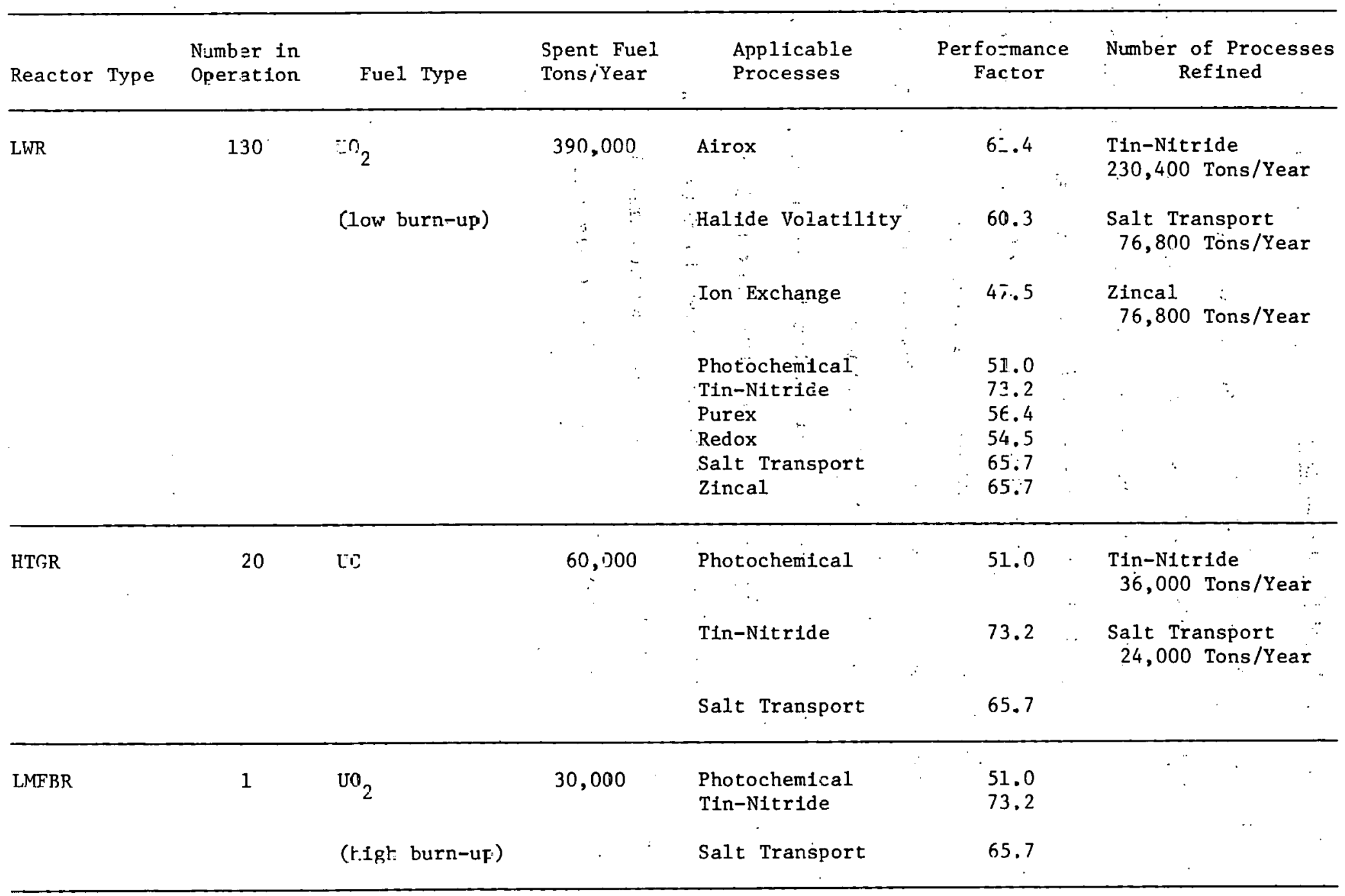


Table 7 (Cont'd)

\begin{tabular}{|c|c|c|c|c|c|c|c|c|c|}
\hline Reactor & Type & $\begin{array}{l}\text { Number in } \\
\text { Operation }\end{array}$ & Fue & 1 Type & & $\begin{array}{l}\text { Spent Fuel } \\
\text { Tons/Year }\end{array}$ & $\begin{array}{l}\text { Applicable } \\
\text { Processes }\end{array}$ & $\begin{array}{l}\text { Performance } \\
\text { Factor }\end{array}$ & $\begin{array}{c}\text { Number of Processes } \\
\text { Refined }\end{array}$ \\
\hline \multirow[t]{3}{*}{ Mis } & & 10 & Metal & Alloys & & 30,000 & Halide Volatility & 60.3 & $\begin{array}{l}\text { Tin-Nitride } \\
18,000 \text { Tons/Year }\end{array}$ \\
\hline & & & & $\therefore$ & $\therefore$ & $\because \quad \ddots$ & Photochemical & 51.0 & $\begin{array}{l}\text { Salt Transport } \\
12,000 \text { Tons/Year }\end{array}$ \\
\hline & & · & $\begin{array}{l}\therefore \\
\therefore\end{array}$ & . & & 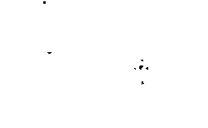 & $\begin{array}{l}\text { Tin-Nitride } \\
\text { Salt Transport }\end{array}$ & $\begin{array}{l}73.2 \\
65.7\end{array}$ & 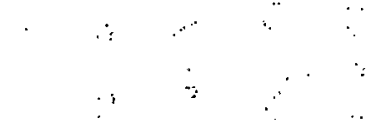 \\
\hline
\end{tabular}

Notes: 1. The Performance Factor (PF) is based on ranking presented in this report in Table 4. To avoid reliance on just a single process the highest PF will share the field with the second highest $P F$ value in 60--40 ratio if a second is available.
2. It is assumed that there is 3000 tons spent fue 1 per year per reactor. 


\section{Conclusions}

An analytic methodology has been developed to compare the performance of various nuclear fuel reprocessing techniques for advanced low proliferation risk fuel cycle applications. The analysis employs 11 subjective descriptors which are given a 1 - 10 rating after an 18 item questionnaire is completed for the process in question. The rating for each descriptor is multiplied by a ranking factor which assigns the desired importance to be given to these descriptors. The sum of the rating and ranking product for all descriptors divided by the maximum potential value gives the numerical figure of performance for the provess.

Through this analytical method, different importance can be assigned to a given item by changing the ranking values. For example, the comparison between the processes could be on cost alone or on environmental safety, regulatory and safeguard considerations alone or any combination of the mix by adjusting the appropriate ranking coefficient from 0 to 10 .

This technique offers an easily applied yet formal approach to gain insight into the effect that a change in external conditions ran produce on $a$ given reprocessing technique. The subjective components can be refined to improve confidence in the analysis when better data becomes available. Tliis methodology has been applied to 14 different reprocessing concepts as a sample illustration. 


\section{$\underline{\text { References }}$}

1. M. Goldstein, et. al.: Waste Management and Proliferation: An Assessment of Technologies and Policies Relevant to Nuclear Power (BNL Report in Preparation).

2. G. Selvaduray (Ph.D. Thesis in preparation).

3. L: J. Colby Jr., et: al.: Comparative Fuel Cycle Evaluation: Low Decontamination Pyroprocessing vs. Aqueous Reprocessing Part 1: $\mathrm{UO}_{2}$ Fuel in a Thermal Reactor. USAEC Technical Report NAA-SR-8036.

4. L. W. Niedrach, A. C. Glanm: Electrorefining for Removing Fission Products From Uranium Fuels, Ind, and Eng. Chem. 48 (6) Jun. 1956 977-981.

5. 0. J. DuTemple, et. al.: Engineering and Economic Consideration of Volatility Processes, Proc. Symp. on the Reprocessing of Irradiated Fuels, Brussels 1957.

6. F. H. Spedding: Decontamination of Uranium, U.S. Patent 3,034,889 May 15, 1962 .

7. W. D. Wilkinson: Uranium Metallurgy Vol. I. Interscience Publishers, N.Y., London. 1962. 542-546.

8. M. Goldstein, et. al.: Assessment and Analysis of Separation Schemes Applied to Reactor Waste Management, March 12, 1975.

9. S. M. Stoller, R. B. Richards, ed.: Reactor Handbook Vol. II, Interscience Publishers, Inc., N.Y. 1961. 324-326.

10. J. H. Schraidt, et. al.: Pyrometallurgical Processing: Economics and Proposed Engineering Applications, Proc. Symp. on the Reprocessing of Irradiated Fuels, Brussels, 1957.

11. D. C. Hampson, et. al.: Melt Refining of ERB-II Fuel, Proc. Symp. on Reprocessing of Nuclear Fuels, Iowa 1969. 57-76.

12. R. N. Anderson: Thermodynamics of Nitride Reactions in Molten UraniumTin Alloy.s and Applications to Nuclear Fuel Reprocessing, Ph.D. Thesis, Stanford University, 1.969.

13. C. J. Joseph, et. al.: Operating Experience and Planned Improvements in the Eurochemic Reprocessing Plant, Proc. 4th Int. Conf. on Peaceful Uses of Atomic Energy, Geneva 1971 Vo1. 8 349-366.

14. S. M. Stoller, R. B. Richards ed: Reactor Handbook, Vol. II. Interscience Publishers, Inc., N.Y. 1961. 131-146. 
15. M. Goldstein, T. Gangwer, C. Braun, and R. Lester, "Technology Assessment and Impact Analysis of Separation Methods Applied to Radioactive Waste Management," BNL 50628, March 1977.'

16. R. K. Steunenberg, et. al.: Status of the Salt Transport Process for Fast Breeder Reactor Fuels, Proc. Symp. on Reprocessing of Nuclear Fuels, Iowa 1969. 325-336.

17. S. M. Stoller, R. B. Richards ed.: Reactor Handbook, Vol. 'II.' Interscience Publishers, Inc., N.Y. 1961. 216-225.

18. W. D. Wilkinson: Uranium Metallurgy, Vol. I. Interscience Publishers Inc. N.Y., London, 1962. 583-599. 
APPENDIX A: AIROX PROCESS ${ }^{(3)}$ 


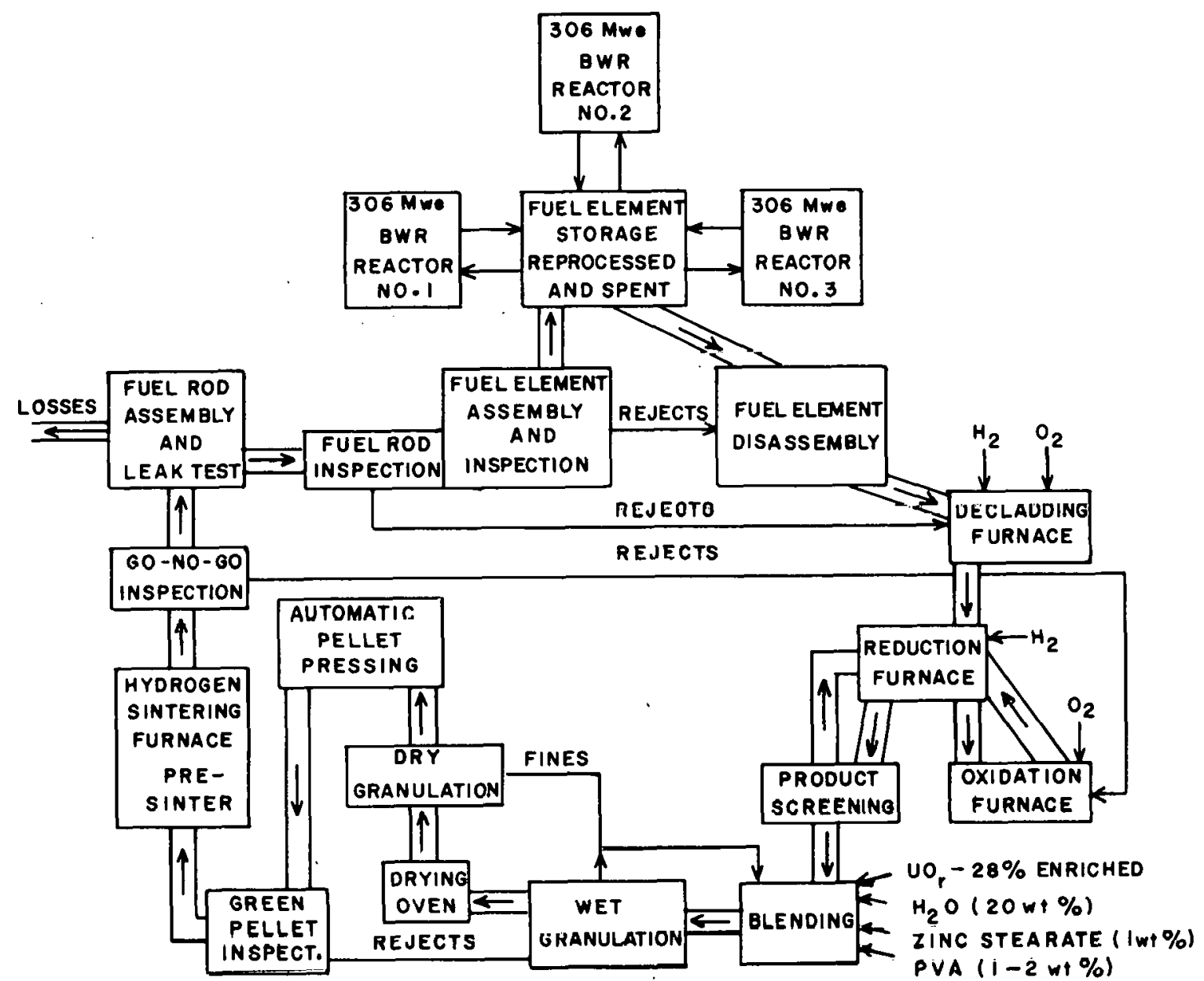

Figure 2. Flowsheet for on-site facility based on the AIROX process. 
1. Cost of Production of $1 \mathrm{Kg}$ (300 MT/year)

$\$ .47 .30$

2. Estimated Capital Cost

3. Separation Factor for fission products

\begin{tabular}{|c|c|}
\hline $\mathrm{Kr}, \mathrm{Xe}, \mathrm{Cs}, \mathrm{I}$ & : $99 \%$ \\
\hline $\mathrm{Ru}$ & $90 \%$ \\
\hline $\mathrm{Tc}, \mathrm{Cd}, \mathrm{In}$ & $50 \%$ \\
\hline Mo, Nb & $2 \%$ \\
\hline
\end{tabular}

4. Fission Product Waste Form: Gaseous

5. Waste Material produced / $\mathrm{Kg}$ fuel reprocessed

No liquids or solids from process

6. Waste radiation level: No data

7. Fuel Type Accommodated: $\mathrm{UO}_{2}$ only

8. Fuel Cooling Requirements: None

9. Breeder Fuel Capability : None

10. Batch or Continuous: Could be either

11. Handling of cladding Material

No Head-End treatment required. After the "oxidation and reduction decladding" step, the cladding material is separated from the $\mathrm{U}_{3} \mathrm{O}_{8}$

12. Form of reprocessed, Material

Sintered pellets

13. Plutonium handling :

Plutonium not separated

14. Handing of radioactive gases :

Collect \& Store

15. Throughput/process inventory

No Data

16. Maximum credible accident

Accidental release of radioactive gases into the atmosphere 

17. Advantages
(1) Rapid reprocessing
(2) No separate head-end treatment required
18. Disadvantages :
(1) Low decontamination; recycle of poisonous f.p. (2) flexibility (adaptability) good only for $\mathrm{UO}_{2}$.
(3) Remote refabrication required

\section{Operating Costs}

1. Annual Plant Costs

$2,089,735$

2. Chemicals

$3,933,000$

3. Labor

4, UUU, UUU

4. Fringe Benefits ( $25 \%$ of 4 )

$1,000,000$

5. Maintenance ( $1 \%$ of Total Capital Costs)

175,000

6. Utilities ( $25 \%$ of 1 )

522,434

7:. Insurance ( $5 \%$ of 1 )

$$
104,487
$$

$11,825,556$

8. Contingencies

$2,365,111$

Total Opcrating Coets

$1.4,190,667$

Cost of lleproccoolng per k.y fuel

$\$ 17.30$ 


\section{Total Capital Costs}

1. Total Process Equipment

$3,354,000$

2. Installation (40\%)

$1,341,600$

3. Instrumentation (10\%)

335,400

4. Bui.1, dings

$4,000,000$

5. Waste Disposal Facility

$2,000,000$

6. Services, Stores and Yards

$1,000,000$

7. Laboratory and Administrative Facilities

$1,500,000$

$13,531,000$

8. Engineering 10\%)

$1,353,100$

9. Contingencies (20\%)

$2,706,200$

Total Capital Cost

$17,590,300$

Annual Plant Cost

$2,089,735$

Process Equipment

1. Furnaces

$1,032,000$

2. Classifiers and Blenders

206,400

3. Granulators

206,400

4. Drying Oven

103,200

5. Sintering Furnace

$1,032,000$

6. Pellet Press

103,200

7. Pellet Inspection Equipment

607,800

Total Process Equipment

$3,354,000$ 


\section{THIS PAGE \\ WAS INTENTIONALLY \\ LEFT BLANK}


APPENDIX B: ELECTROCHEMICAL SALT REPROCESSING ${ }^{(4)}$ 


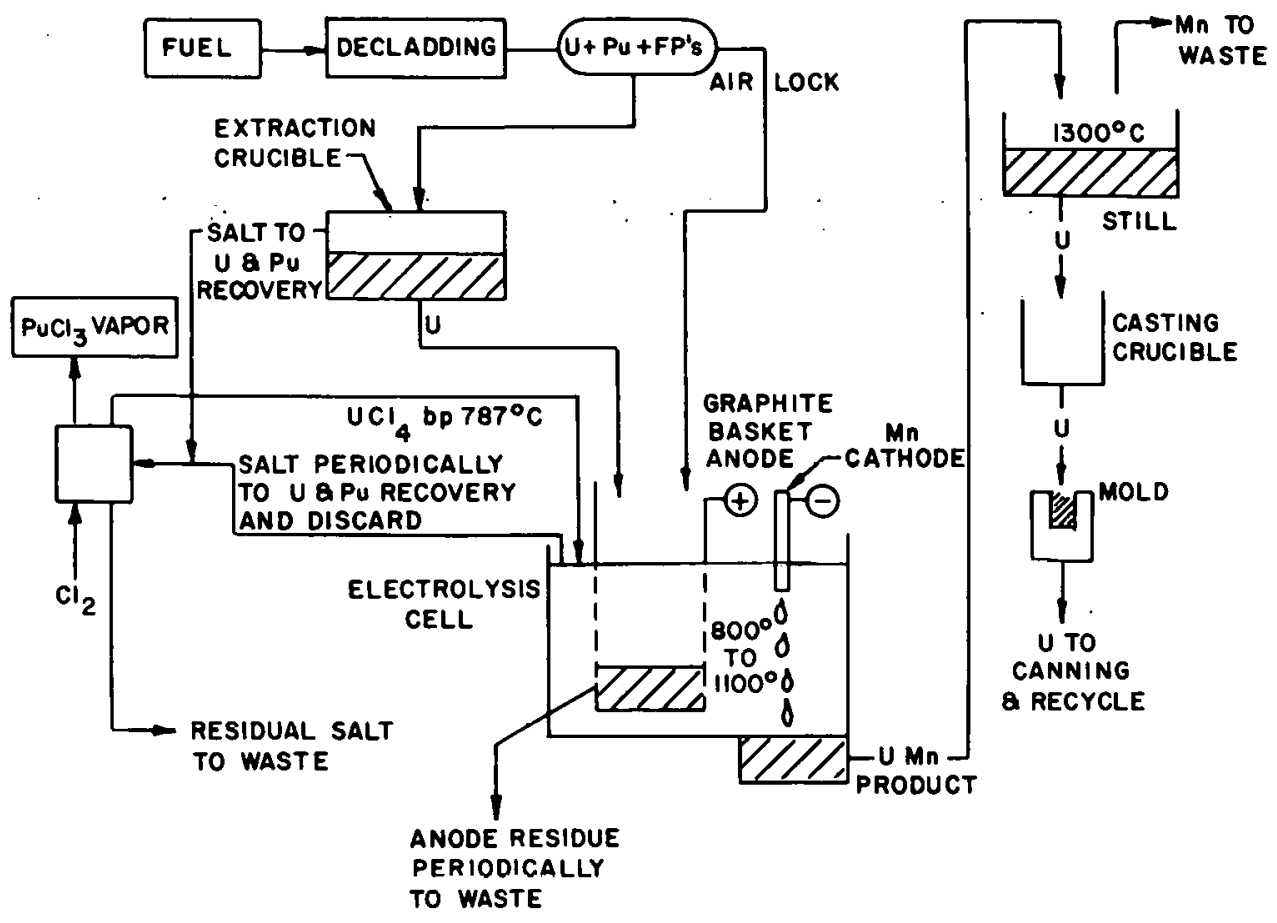

Figure 3. Proposed fused salt electrolysis system of reprocessing involving a dripping mangancse cathode. 
1. Cost of Production of $1 \mathrm{~kg}$ (300 MT/Year): $\$ 13.55$

2. Estimated Capital Cost: : $\$ 12,480,000$

3. Separation Factor for Fission products

Decontamination Factor: $10^{2} \simeq 10^{3}$ f.p. close to $U$, cannot be separated electrolytically.

4. Fission Product Waste Form: Salt; active f.p. in salt, noble f.p. metallic anode muds.

5. Waste material produced $/ \mathrm{kg}$ fuel reprocessed:

$1 / 25 \mathrm{~kg}$, Anode residue and residual salt.

6. Waste radiation level:

3.5 watts/cc

7. Fue1-Type Accomodated:

Metallic

8. Fuel cooling requirements:

None

9. Breeder Fuel Capability:

Yes, if metallic

10. Batch or continuous:

Probably batch

11. Handiing of cladding material: Head-End Treatment required

12. Form of reprocessed material: Metal alloy which can be converted to oxide or hexafluoride if desired

13. Plutonium handling:

Pu can be separated or can go with the uranium; separate extraction step required

14. Handling of radioactive gases: Very effective for gases, since nonobscuring of tritium, etc.

15. Throughput/process inventory:

$1 \mathrm{~kg}$ fuel day/ $1 \mathrm{~kg}$ molten salt

16. Maximum credible accident:

Salt loses heat and batch is dumped as solid

17. Advantages:

(1) Can handle 1 in short cooled fuel.

(2) Can work with thorium

18. Disadvantages:

(1) Corrosion problems

(2) Applicable to limited (metallic) fuel types.

(3) Contamination of $U$ resulting in further refining being required.

(4) Remote refabrication required. 
1. Annual Plant Costs

2. Mn Consumption

3. Salt Consumption

4. Utilities

5. Personnel 40 at $\$ 20,000$ p.a.

6. Fringe Benefits ( $25 \%$ of 5 )

7. Maintenance ( $1 \%$ of Total Capital Costs)

8. Insurance ( $5 \%$ of 1 )

9. Contingencies

Total Operating Costs

Cost of Reprocessing per kg fuel
$1,482,629$

35,400

300,000

370,657

800,000

200,000

124,800

74,131

$3,387,617$

677,523

$4,065,140$

$\$ 13.55$ 
1. Process Equipment

2. Installation

3. Instrumentation ( $10 \%)$

4. Buildings $20,000 \mathrm{ft}^{2}$ @ $\$ 30 / \mathrm{ft}^{2}$

5. Waste Disposal Facilities

6. Services, Stores and Yards

7. Laboratory and Administrative Facilities

8. Engineering

9. Contingencies

Total Capital Costs

Annual Plant Costs

$$
\begin{array}{r}
3,000,000 \\
1,200,000 \\
300,000 \\
600,000 \\
2,000,000 \\
1,000,000 \\
1,500,000 \\
\hline 9,600,000 \\
960,000 \\
1,920,000 \\
\hline 12,480,000 \\
\hline 1,482,629
\end{array}
$$

\section{Process Equipment}

1. Electrolytic Cell with supporting equipment and shielding

$1,500,000$

500,000

3. Salt Recycle and Pu recovery by Chlorination

$$
1,000,000
$$

Total Process Equipment 
THIS PAGE

\section{WAS INTENTIONALLY LEFT BLANK}




\section{APPENDIX C: HALIDE VOLATILITY (5)}

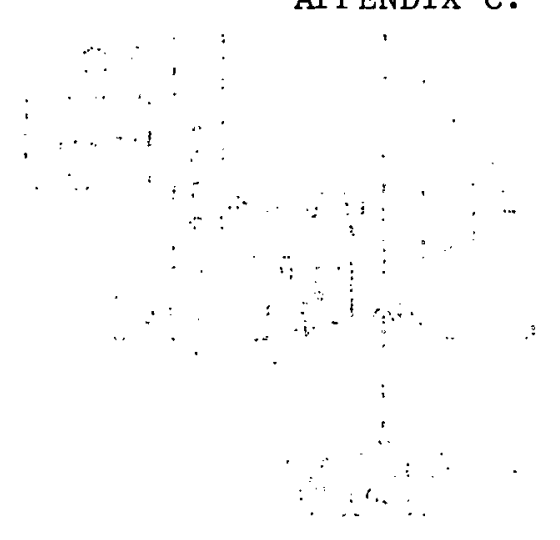




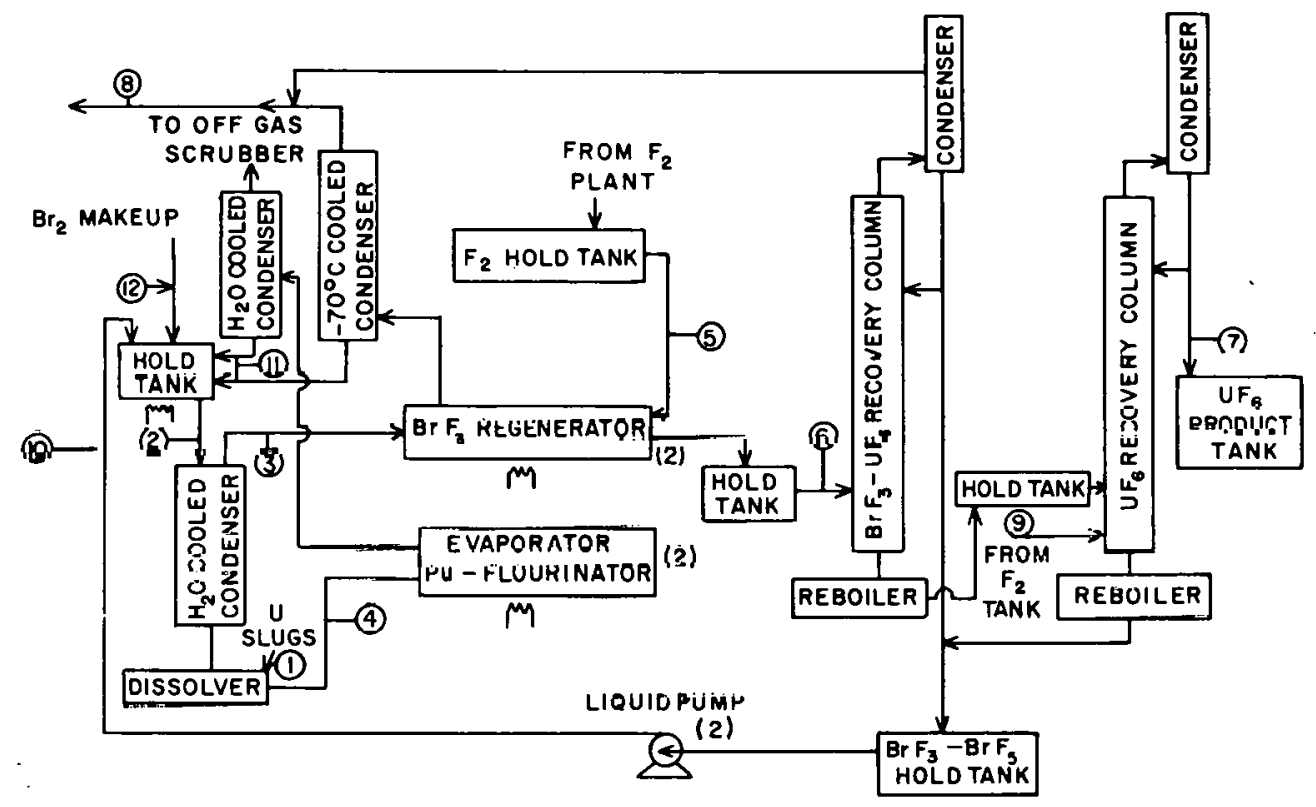

Figure 4. Bromine trifluoride method, $\mathrm{BF}_{3}$ regeneration and uranium purification. 
1. Cost of Production of $1 \mathrm{Kg}$ fuel (300 MT/year)

2. Estimated Capital Cost

3. Separation factor for fission products

Decontamination factor: $10^{8}$

4. Fission Product Waste Form:

5. Waste Material produced per $\mathrm{Kg}$ fuel reprocessed $\simeq 0.5 \mathrm{gal} / \mathrm{Kg}$ high level wastes

6. Waste radiation level:

7. Fue1 Type accommodated:

8. Fuel cooling requirements:

9. Breeder Fuel Capability:

10. Handling of cladding materials, possible to declad while fluorinating, preferable to have separate head-end treatment

11. Continuous

12. Form of reprocessed material:

13. Pu handling

14. Handling of radioactive gases:

15. Throughput/process inventory :

16. Maximum credible Accident :
$\$ 27.64$

$\$ 20,811,389$

Fluorides--Volatile and non volatile and gases

Metallic, oxide U, Pu, Th Molten salt poiisble None

Yes

$\mathrm{UF}_{6}$

Can be separated as the fluoride

Collect and Store

In addition to ordinartly gaseous f.p. the volatile f.p. could be released into the atmosphere. Liquid f.p. could spill. 


\section{Halide Volatility (Continued)}

17. Advantages

18. Disadvantages:

\section{Operating Costs}

1. Annual Plant Cost

2. Chemicals

3. Labor 100 \& $\$ 20,000$ p.a.

4. Fringe Benefits (at $25 \%$ of 4 )

5. Maintenance ( $1 \%$ of Total Cap1tal Costs)

6. Itrilities $(25 \%$ of 1$)$

7. Insurance ( $5 \%$ of 1 )

8. Contingencies (20\%)

Total Operating Costs

Coet of Reprucusiling per kg liuel
(1) UF 6 can be sent 'directly to enrich-" ment plant

(2) High decontamination

(1) Accident risk very high-volatile f.p.

(2) Corrosion problems. 
1. Process Equipment

$$
\begin{array}{r}
4,672,510 \\
1,869,000 \\
467,251 \\
3,500,000 \\
2,500,000 \\
1,000,000 \\
1,500,000 \\
500,000 \\
\hline 16,008,761 \\
1,600,876 \\
3,201,752 \\
\hline 20,811,389 \\
\hline 2,472,401
\end{array}
$$$$
\text { 2. Installation and Overheads (40\%) }
$$$$
\text { 3. Instrumentation ( } 10 \%)
$$$$
\text { 4. Buildings }
$$

5. Waste Disposal Facility

6. Services, Stores, and Yards

7. Laboratory and Administrative Facilities

8. Chemical Make-up and Storage

9. Engineering (10\%)

10. Contingencies (20\%)

Total Capital Costs

Annual Plant Cost

\section{Process Equipment}

1. Uranium dissolution, solvent Regeneration and $\mathrm{UF}_{6}$ purification

$1,592,916$

150,148

2. Pu recovery and purification

3. Scrubber

4. Fluorine Plant

Total Process Equipment

$$
63,772
$$

$2,865,674$

$4,672,510$ 
THIS PAGE

\section{WAS INTENTIONALLY LEFT BLANK}


APPENDIX D: HYDRIDE PROCESS ${ }^{(6)}$ 


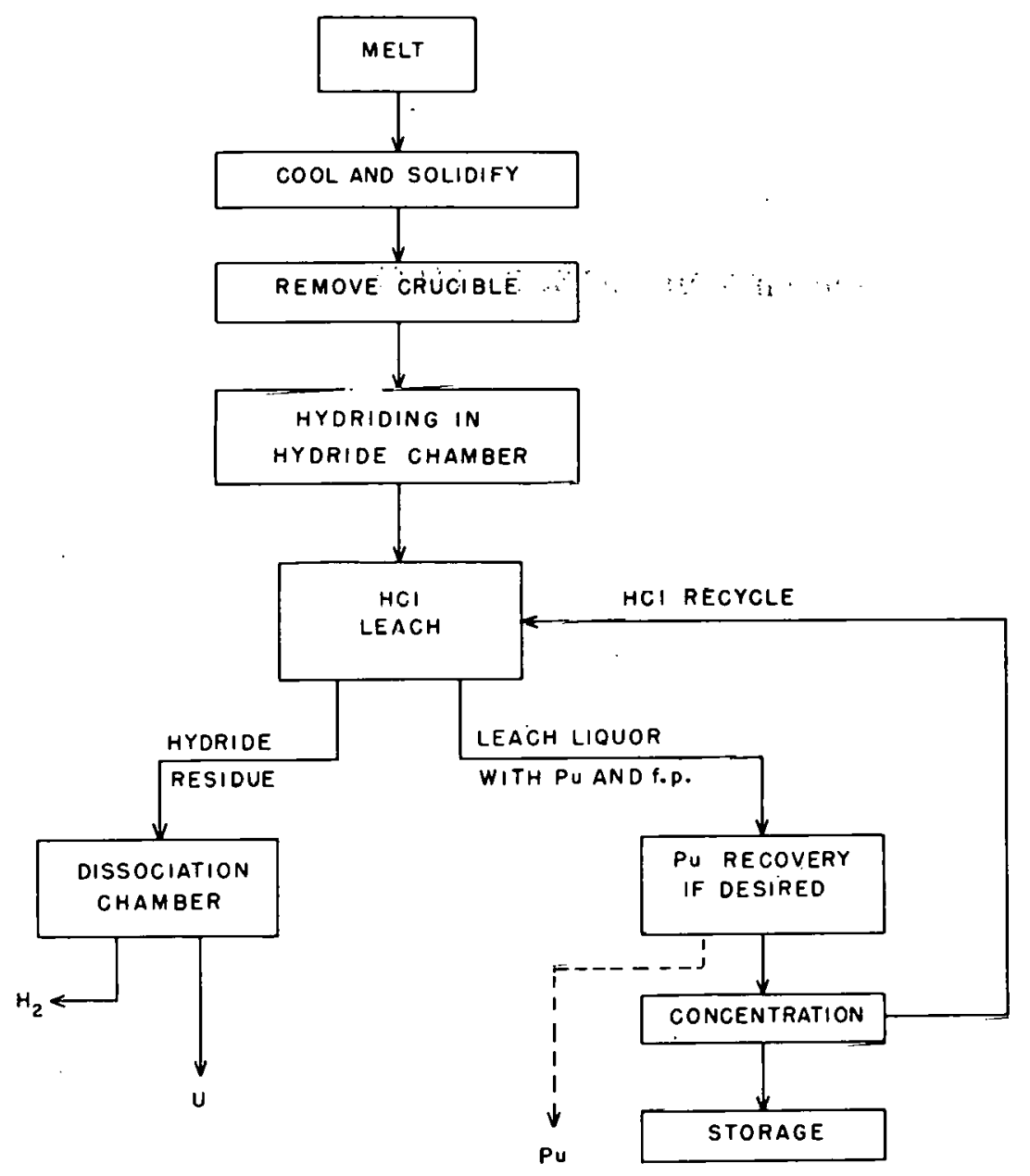

Figure 5. Hydride reprocessing schemes as visualized by the aluthore. 
1. Cost of Production of $\mathrm{Kg}$ (300 MT/Year)

2. Estimated Capital Cost

3. Separation factor for fission products

4. Fission product waste form:

5. Waste material produced per $\mathrm{kg}$ fuel reprocessed:

6. Waste radiation level:

7. Fuel type accommodated:

8. Fuel cooling requirements:

9. Breeder Fuel Capability:

10. Batch or continuous process:

11. Handling of cladding material:

12. Form of reprocessed material:

13. Plutonium handling:

14. Handling of radioactive gases:

15. Throughout/process inventory:

16. Maximum credible accident:

17. Advantages:

18. Disadvantages:
$\$ 18.87$

$\$: 16,558,750$

Poor (probably $10^{2} \simeq 10^{3}$ )

Intermetallic solid containing f.p.

$\simeq 0.2 \simeq 0.3 \mathrm{Kg}$, predominantly uranium. Also gases

No Data

Metallic; uranium only

None

None

Batch

Head-end Treatment necessary

Uranium Hydride

No specific separation

Should be collected during initial melting

$\mathrm{Sn}_{2} \mathrm{Cl}_{2}$

Release of radioactive gases into atmosphere

(1) Rapid reprocessing

(2) No liquid waste

(1) Suitable only for metallic uranium

(2) Low decontamination

(3) Hydriding in solid state-slow reaction kinetics

(4) Possible use of silver could be very expensive

(5) High loss of U, Pu

(6) Very primitive 
1. Annual Plant Costs

$1.967,186$

2. Sn Consumption

113,960

3. $\mathrm{HCl}$ and $\mathrm{H}_{2}$ consumption

280,000

4. Crucibles

350,000

5. Utilities ( $25 \%$ of 1 )

491,800

6. Persomel 50 at $\$ 20,000$ p.a

$1,000,000$

7. Fringe Benefits ( $25 \%$ of 6 )

250,000

8. Malntenance ( $1 \%$ of Tria Capital costs)

165,588

9. Insurance ( $5 \%$ of 1$)$

98,359

$4,716,893$

10. Contingencies

943,379

Total Operating Costs

$5,660,272$

Coat of Reprocessing per $\mathrm{Kg}$ fuel

$\$ 18.87$ 
1. $200 \mathrm{~kg}$ Induction Furnace with support 750,000 equipment and shielding

2. Crucible removal

$1,000,000$ Remote controlled

$1,500,000$

3. Hydriding Chamber

325,000

4. HCl leach tank 500,000

5. Dissociation Chamber 350,000

6. HCl Recycle

$4,425,000$

\section{Consumable Items}

1. Crucibles $(300+500) \mathrm{ZrO}_{2}$ ( $\$ 100$ each 350,000 $10 \mathrm{~cm} \mathrm{x} 10 \mathrm{~cm} \times 50 \mathrm{~cm}$

2. Sn consumption $14,800 \mathrm{~kg} @ \$ 7.70 / \mathrm{kg}$ 250,000

3. $\mathrm{HCl}$ 30,000

4. Hydrogen

$1,033,960$


THIS PAGE

\section{WAS INTENTIONALLY \\ LEFT BLANK}


APPENDIX E: ION EXCHANGE ${ }^{(7)}$

$-59-$ 


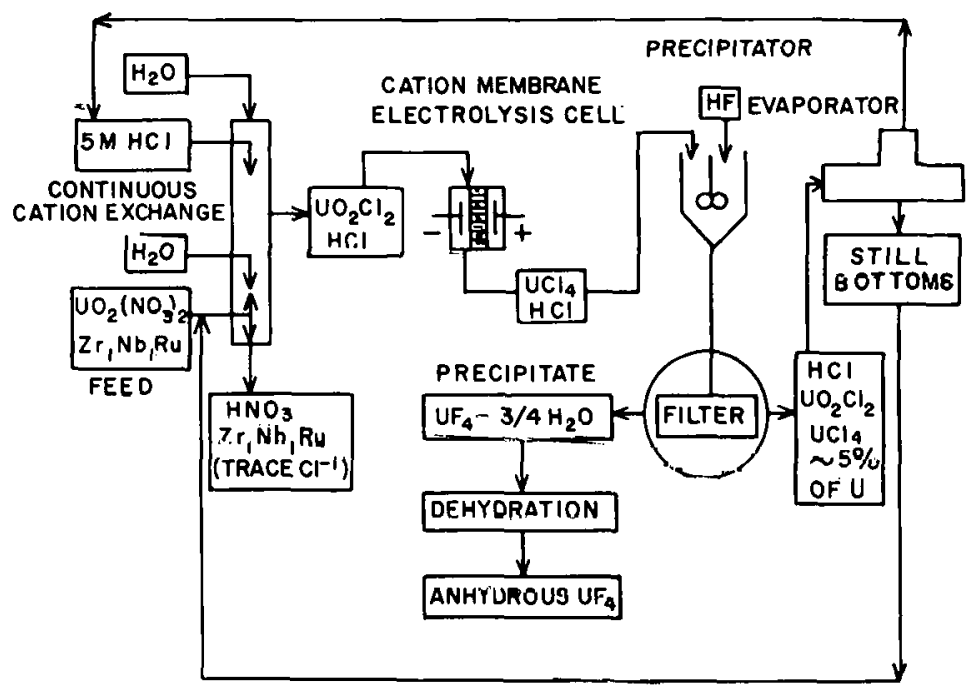

Figure 6. Excer process of reprocessing in which uranium in fuels is converted to uranyl nitrate solution and is separated from alloying element and fission products by cation exchange and electrolytic reduction and precipitation. 
1. Cost of production of $1 \mathrm{~kg}$ (300 MT/year)

2. Estimated Capital Cost

3. Separation Factor for fission products Decontamination Factor:

4. Fission Product Waste form:

5. Waste Material produced per $\mathrm{kg}$ fuel reprocessed

6. Waste radiation level:

7. Fuel type accommodated:

8. Fuel cooling requirements:

9. Breeder Fuel Capacity:

10. Continuous

11. Form of reprocessed material:

12. Handling of cladding material:

13. Plutonium handling:

14. Handling of radioactive gases:

15. Throughput/process inventory:
$\$ 48,53$

$\$ 26,318,500$

$10^{5}-10^{6}$

Aqueous soln, and gases from dissolution

No Data

Metallic, oxide; basically any fuel that will dissolve in $\mathrm{HNO}_{3}$ to form $\mathrm{UO}_{2}\left(\mathrm{NO}_{3}\right)_{z}$

Depends upon resins and membranes. Generally radiation should not exceed $1 \sim 4.5$ watt-hr per gram of dry resin $\left(0.38 \times 10^{9} \sim 1.7 \times 10^{9} \mathrm{r}\right)$

Aqueous homogenous reactor-maybe LMFBR and MSBR-NO

Anhydrous $\mathrm{UF}_{4}$

Head-End treatment required

Though the Excer process does not include $\mathrm{Pu}$ separation this is possible by adding another Ion Exchange stage using silica-gel, pretreated with an aqueous reducing agent and $30 \mathrm{v} / \mathrm{v}$ TBP

Collect and Store 


\section{Ion Exchange (Continued)}

16. Maximum credible Accident:

17. Advantages:

18. Disadvantages:
Spill of liquids and subsequent seepage to watertable could result in large scale contamination

(1) Can be applied to specific purposes; e.g., tail-end $\mathrm{Pu}$ separation

(2) Good selectivity, and thus higher over-all product concentration

(3) Smaller reagent requirement compared to other aqueous processes.

(1) Resin susceptible to : radiation damage therefore precooling required

(2) Liquid Wastes

(3) Loss of $\simeq 5 \%$ of uranium

\section{Operating Costs}

1. Annual Plant Cost

2. Chemleals and Rcagents

3. Utilities ( $25 \%$ of 1$)$

4. Personnel 200 at $\$ 20,000$ p.a.

5. Fringe Benefits (at $25 \%$ of 4 )

6. Maintenance ( $1 \%$ of Total Capital Cost)

7. Insurance ( $5 \%$ of 1$)$

8. Contingencies (20\%)

Total Operating Cost

Cost of Reprocessing per $\mathrm{kg}$ fuel

$$
\begin{array}{r}
3,126,648 \\
2,803,9511 \\
181,662 \\
4,000,000 \\
1,000,000 \\
263,185 \\
156,332 \\
\hline 12,131,777 \\
: \\
2,426,355 \\
\hline 14,558,132 \\
\hline \$ 48.53
\end{array}
$$


1. Chemical Make-up and Storage

500,000

2. Process Equipment

$6,830,000$

3. Installation and Overheads ( $40 \$$ of 2 )

$2,732,000$

4. Instrumentation ( $10 \%$ of 2 )

683,000

5. Buildings

$3,000,000$

6. Liquid and Waste Disposal Tanks

$4,000,000$

7. Services, Stores, and Yards

$1,000,000$

8. Laboratory and Administrative

$1,500,000$

$20,245,000$

9. Engineering (10\%)

$2,024,500$

10. Contingencies (20\%)

$4,049,000$

$\overline{26,318,500}$

Annual Plant Cost

$3,126,648$

Process Equipment

1. Dissolution Tank

325,000

2. Ion Exchange Columns

$2,500,000$

3. Electrolysis Cell

$1,500,000$

4. Precipitator

300,000

5. Evaporator

400,000

6. Filter

70,000

7. $\mathrm{HCl} \& \mathrm{HNO}_{3}$ Recycle

100,000

8. Pipes, Valves and Fittings ( $50 \%$ of $2,4,5$ and 6 )

$1,635,000$

Total Process Equipment

$6,830,000$ 
THIS PAGE

\section{WAS INTENTIONALLY \\ LEFT BLANK}


APPENDIX F: PHOTOCHEMICAL (8)

$-65-$ 


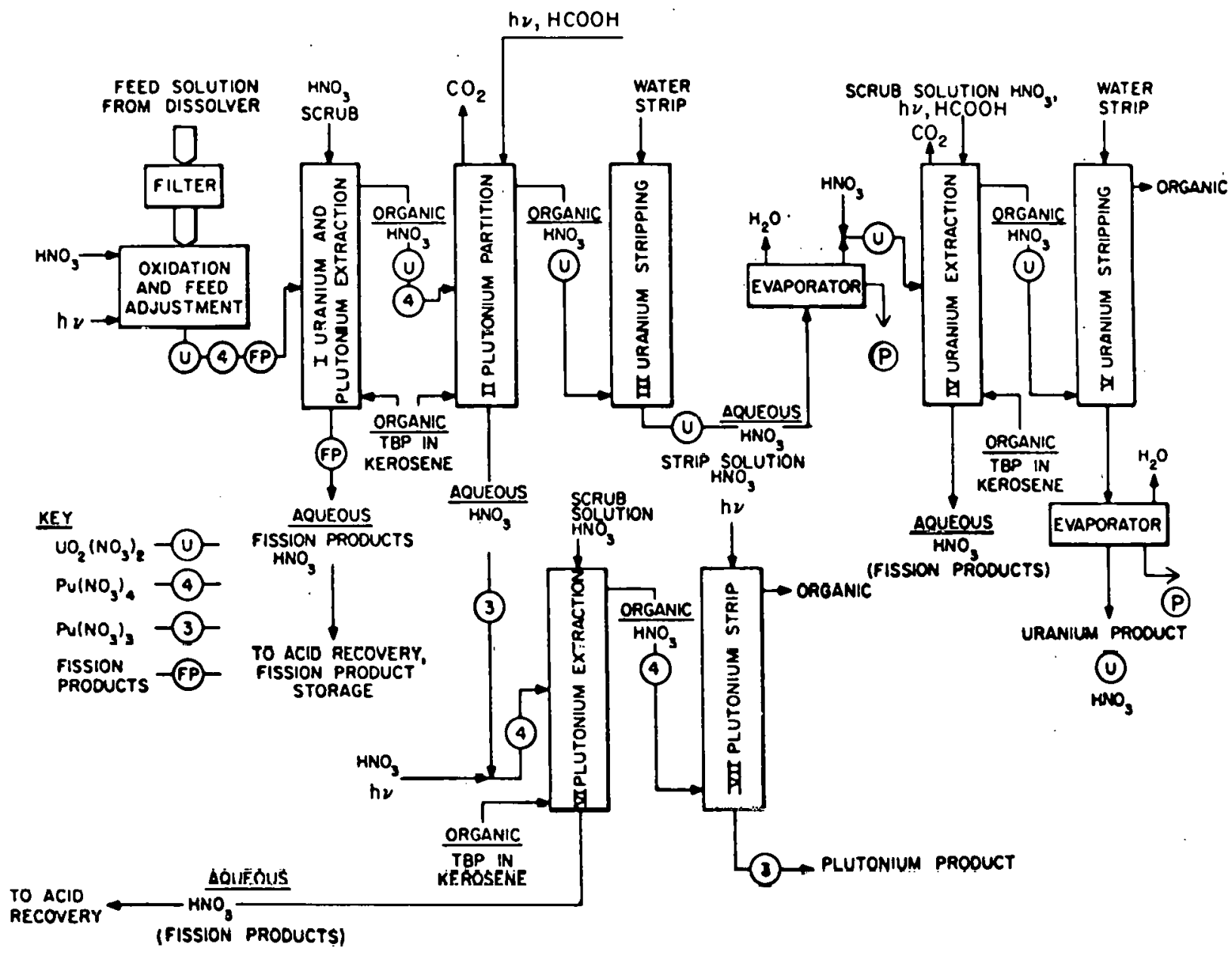

Figure 7. Flow chart of photochemically modified purex process for treatment of low enriched uranium fuel (9). 
1. Cost of Production of $1 \mathrm{~kg}$ (300 MT/year) $\$ 57.73$

2. Estimated Capital Cost

3. Separation factor for fission products:

Decontamination Factor: $\simeq 10^{8}$

4. Fission product waste form:

Basically liquid, and ràre gases from dissolution - ref. Purex

5. Waste Material produced per $\mathrm{kg}$ fuei reprocessed:

Half the volume of Purex waste

6. Waste radiation level:

No data

7. Fuel Type accommodated:

Any type, so long as oxidationreduction can be photochemically induced

8. Fuel cooling requirements

None

9. Breeder Fuel Capability:

Yes

10. Continuous

11. Handling of cladding material:

Head-End treatment required

12. Form of reprocessed material:

Liquid. If $\mathrm{HNO}_{3}$ dissolution is employed then probably uranyl nitrate

13. Plutonium handling:

$\mathrm{Pu}$ can be isolated in a relatively pure form. Solution can be treated to obtain desired chemical form

14. Handling of radioactive:

Collect and store

15. Throughput/process inventory:

No data

16. Maximum credible accident:

Spill of liquid solution could result in seepage down to water table

17. Advantages:

(1) High decontamination

(2) Good separation of f.p. depending upon their lives

18. Disadvantages:

(1) Low energy efficiency

(2) Liquid wastes 
1. Annual Plant Costs

$3,364,638$

2. Reagents for Dissolution (estimate)

$5,000,000$

3. Utilities ( $25 \%$ of 1 )

841,159

4. Personnel 190 at $\$ 20,000$ p.a.

$3,800,000$

5. Fringe Benefits (at $25 \%$ of 4 )

950,000

6. Maintenance ( $1 \%$ of Total Capital cost)

309,043

7. Insurance ( $5 \%$ of 1 )

168,232

$14,432,722$

8. Contingencies (20\%)

$2,886,554$

Total Operating Costs

$\underline{17,319,326}$

Cost of Reprocessing per kg fuel

$\$ 57.73$ 
1. Dissolution Tank

504,609

2. Process Equipment (stage 1)

$4,133,140$

3. Process Equipment ( 3 more stages each costing $40 \%$ stage 1 )

$4,959,768$

4. Installation ( $40 \%$ of 2 and 3 )

$3,306,510$

5. Buildings $50,000 \mathrm{ft}^{2}$ @ $\$ 30 / \mathrm{ft}^{2}$

$2,328,967$

6. Waste Disposal Facilities

$4,657,934$

7. Services, Stores and Yards

$1,552,645$

8. Laboratory and Administrative Facility

$2,328,967$

$23,772,540$

9. Engineering (10\%)

$2,377,200$

10. Contingencies (20\%)

4,754,510

Total Capital Costs

$\underline{30,904,300}$

Annual Plant Cost

$3,364,638$

Processing Equipment

Stage 1 .

1. Photoexcitation Equipment

$1,027,851$

2. Solvent Separation

$2,328,967$

3. Photochemical reactors

776,322

Total Processing Equipment

$4,133,140$ 
THIS PAGE

\section{WAS INTENTIONALLY} LEFT BLANK 
APPENDIX G: LIQUID-LIQUID PARTITIONING ${ }^{(9)}$ 
1. Cost of production of $1 \mathrm{~kg}$ (300 MT/year)

2. Estimated Capital Cost:

3. Separation Factor for fission products Decontamination Factor: $\simeq 10^{3}$

4. Fission Product Waste Form:

5. Waste Material produced per $\mathrm{kg}$ fue1 reprocessed:

G. Waste radiation level

7. Fuel type accommodated:

8. Fuel Cooling requirements:

9. Breeder Fuel Capability:

10. Batch

11. Handling of cladding material:

12. Form of reprocessed material:

13. Plutonium Handling:

14. Handling of radioactive gases:

15. Throughput/process inventory

16. Maximum credible accidnet:

17. Advalliages:

18. Disadvantages:
Solid and Gases

$\simeq 0.4 \mathrm{~kg} \mathrm{Mg}$ assuming the Uranium and Magnesium are recovered and recycled respectively

Metallic $\mathrm{U}$ and $\mathrm{Pu}$ and $\mathrm{Th}$

None

No

Head-End Treatment necessary

$\mathrm{Pu}$-- slightly contaminated with $\mathrm{Mg}$ U -- slightly contaminated with $\mathrm{Mg}$ (aoouming f.p. is separate.d from $U$ )

$\mathrm{Pu}$ is selectively separated

Collect and store

Kelease of radiodullve gases linto the atmosphere

(1) Rapid reproscocing

(2) Economic advantage

(3) No liquid wastes

(1) Dependent upon $\mathrm{Mg}$ supply

(2) Low decunlamination

(3) Corrosion of equipment by liquid metals. 


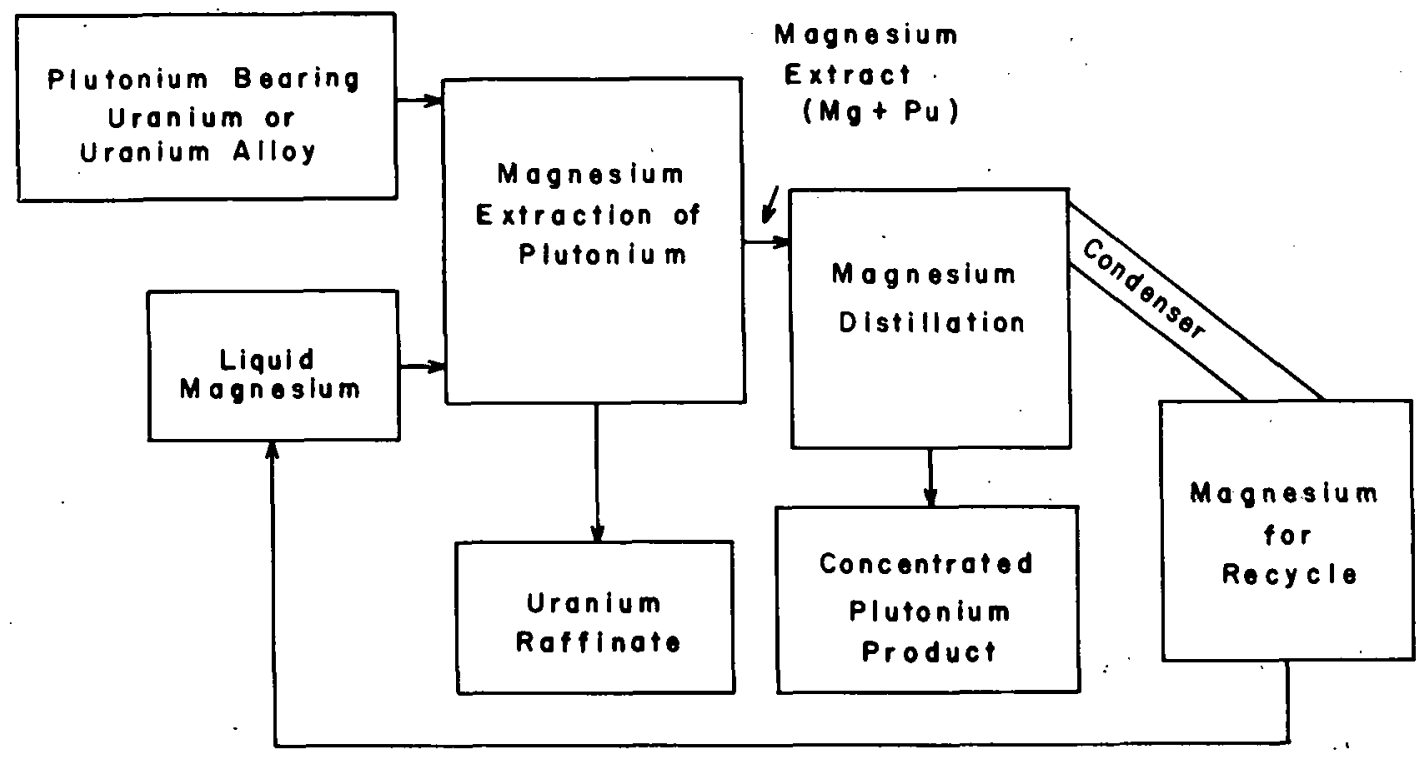

Figure 8. Schematic flowsheet for magnesium extraction of plutonium from molten uranium. 
1. Annual Plant Cost 2 year deferment followed by 20 year straight line depreciation at $8 \%$ interest p.a.

2. Magnesium Consumption (at $8 \%$ loss per cycle) $275,725 \mathrm{~kg}$ @ \$2.07 per $\mathrm{kg}$

3. Utilities ( $25 \%$ of 1$)$ 340,363

4. Personnel 40 at $\$ 20,000$ p.a.. 800,000

5. Fringe Benefits (at $25 \%$ of 4 ) 200,000

6. Maintenance ( $1 \%$ of Total Capital cost) 114,600

7. Insurance $(5 \%$ of 1$)$ 68,072 $\overline{3,454,685}$

8. Contingencies (at 20\%) 690,937

Total Annual Operating Cost $4,145,622$ Cost of Reprocèssing per kg fuel 
1. Processing Equipment

2. Installation \& Overheads (at $40 \%$ of 1 )

3. Instrumentation (at $10 \%$ of 1 )

4. Buildings (1500 $\mathrm{ft}^{2}$ @ $\$ 30 / \mathrm{ft}^{2}$ )

5. Services, Stores and Yards

6. Laboratory and Administrative Facilities

7. Waste Disposal Facilities

8. Contingencies (at 20\%)

Total Capital Costs

Annual Plant Costs

$$
\begin{array}{r}
3,400,000 \\
1,360,000 \\
340,000 \\
450,000 \\
1,000,000 \\
1,500,000 \\
1,500,000 \\
\hline 9,550,000 \\
1,910,000 \\
\frac{11,460,000}{1,316,453}
\end{array}
$$

\section{Process Equipment}

1. 7 ton Furnace including support equipment and shielding

2. Mg distillation equipment

3. Mg Recycle equipment

4. $\mathrm{Pu}$ and $\mathrm{U}$ receivers

Total Process Equipment
500,000

$1,200,000$

200,000

$1,500,000$

$\underline{3,400,000}$ 


\section{THIS PAGE}

\section{WAS INTENTIONALLY LEFT BLANK}


APPENDIX H: MELT REFINING $(10,11)$

$-77-$ 


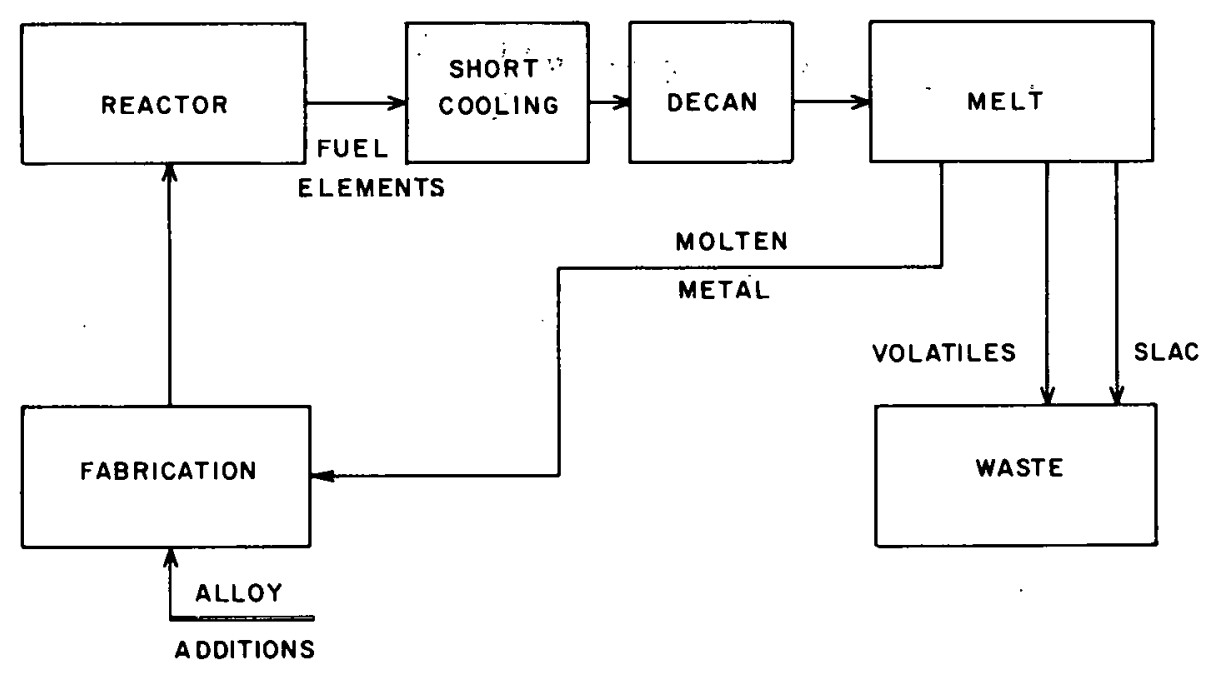

Figure 9. Melt refining cycle. 


\section{Melt Refining}

1. Cost of production of $1 \mathrm{~kg}$ ( $330 \mathrm{MT} / \mathrm{yr}$ plant)

2. Estimated Capital Cost

3. Separation factor for Fission Product

Decontamination Factor:

$\simeq 10^{2}$

On heating, $\mathrm{Xe}, \mathrm{Kr}, \mathrm{Cs}, \mathrm{Cd} \& \mathrm{Ru}$ removed $100 \%$. More than $75 \%$ I removed.

Product composition:

4. Fission Product Waste Form:

5. Waste material produced $/ \mathrm{kg}$ fuel reprocessed:

6. Waste radiation level

Input Radioactivity

Products:

Ingot
Crucible skull
Fumes

Ingot

Fumes

ted :

7. Fuel type accommodated:
$\$ 30.87$

$\$ 39,154,932$
U: $\quad 90 \simeq 95 \%$ of original content $\mathrm{Pu}: 90 \simeq 95 \%$

Noble metals: $90 \simeq 95 \%$

Gaseous and Solid

Xe, $\mathrm{Kr}$, Fume trap, skul: ( $5 \simeq 10 \%$ of charged material), ingot mould and crucible

$7 \times 10^{4} \mathrm{R} / \mathrm{hr}$

$4.5 \times 10_{4}^{3} \mathrm{R} / \mathrm{hr}(8 \%)$

$5.0 \times 10_{3}^{4} \mathrm{R} / \mathrm{hr}(84 \%)$

$4.0 \times 10^{3} \mathrm{R} / \mathrm{hr}(8 \%)$

\begin{tabular}{lrcc}
\multicolumn{2}{c}{ Metallic Uranium Process operated at $1400^{\circ} \mathrm{C}}$. \\
Material & Melting Point & Material & Melting Point \\
\hline Uranium & $1132^{\circ} \mathrm{C}$ & $\mathrm{U} 0$ & $2700^{\circ} \mathrm{C}$ \\
Plutonium & $640^{\circ} \mathrm{C}$ & $\mathrm{Zr}^{2}$ & $1852^{\circ} \mathrm{C}$ \\
Thorium & $1750^{\circ} \mathrm{C}$ & & \\
UC & $<2200^{\circ} \mathrm{C}$ & & \\
UN & $<2600^{\circ} \mathrm{C}$ &
\end{tabular}


8. Fuel Cooling requirements

9. Breeder Fuel Capability:

10. Batch or continuous:

11. Handling of cladding materials:

12. Form of reprocessed material:

13. Plutonium handling

14 Handling of radioactive gases

15. Throughput/process inventory:

16. Maximum credible Accident:

17. Advantages:

18. Disadvantages:
None in particular; however, as burn-up increases, pouring yield decrease. Therefore, probably beneficial to have precooling period.

If metallic, yes, if oxides, or mixed oxides, no.

Batch

Head-End Treatment required. Simultaneous Metal Refining Zr highly improbable

Basicaly ingot

$\mathrm{Pu}$ not isolated

Collected, then released to atmosphere through $200 \mathrm{ft}$ stack

Solidification of molten mass

(1) Rapid Reprocessing

(2) No additional Fabrication required

(3) No liquid wastes

(1) Separation factor very bad

(2) Remote control required for refabrication of fuel elements

(3) High fuel loss 


\section{Operating Costs}

1. Annual Plant Cost

$4,651,621$

2. Chemicals

$1,000,000$

3. Utilities ( $25 \%$ of 1 )

$1,162,905$

4. Personnel 40 at $\$ 20,000$ p.a.

800,000

5. Fringe Benefits (at $25 \%$ of 4 )

200,000

6. Maintenance ( $1 \%$ of Total Capital Costs)

391,549

7. Insurance ( $5 \%$ of 1 )

232,581

$7,718,656$

8. Contingencies

$1,543,731$

Total Operating Costs

$9,262,387$

Costs of Reprocessing per kg fuel

$\$ 30.87$ 
1. Process Equipment

$13,538,460$

2. Installation (40\%)

$5,415,384$

3. Instrumentation (10\%)

$1,353,846$

4. Buildings

$2,416,128$

5. Process Cell Construction

$2,89.5,36 n$

6. Waste Dispusal Facliletes

$2,000,000$

7. Services, Stores and Yards

$1,000,000$

8. Laboratory and Administrative Facilities

$1,500,000$

$\overline{30,119,178}$

9. Engineering (10\%)

$3,011,918$

10. Contingencies (20\%)

$6,023,836$

Total Capita.1. Cost

$\overline{39,154,932}$

Annuả 1 Plant Cost

$4,651,621$

Process Equijucul

1. Process Cell Service Equipment

$3,525,600$

2. Process Cel1 Equipment

$2,246,400$

3. Process Equipment

$5,800,860$

1. Supporting Finipment

$1,965,600$

Total Process Equipment

$\overline{13,538,460}$ 
APPENDIX I: TIN-NITRIDE (12)

$-83-$ 


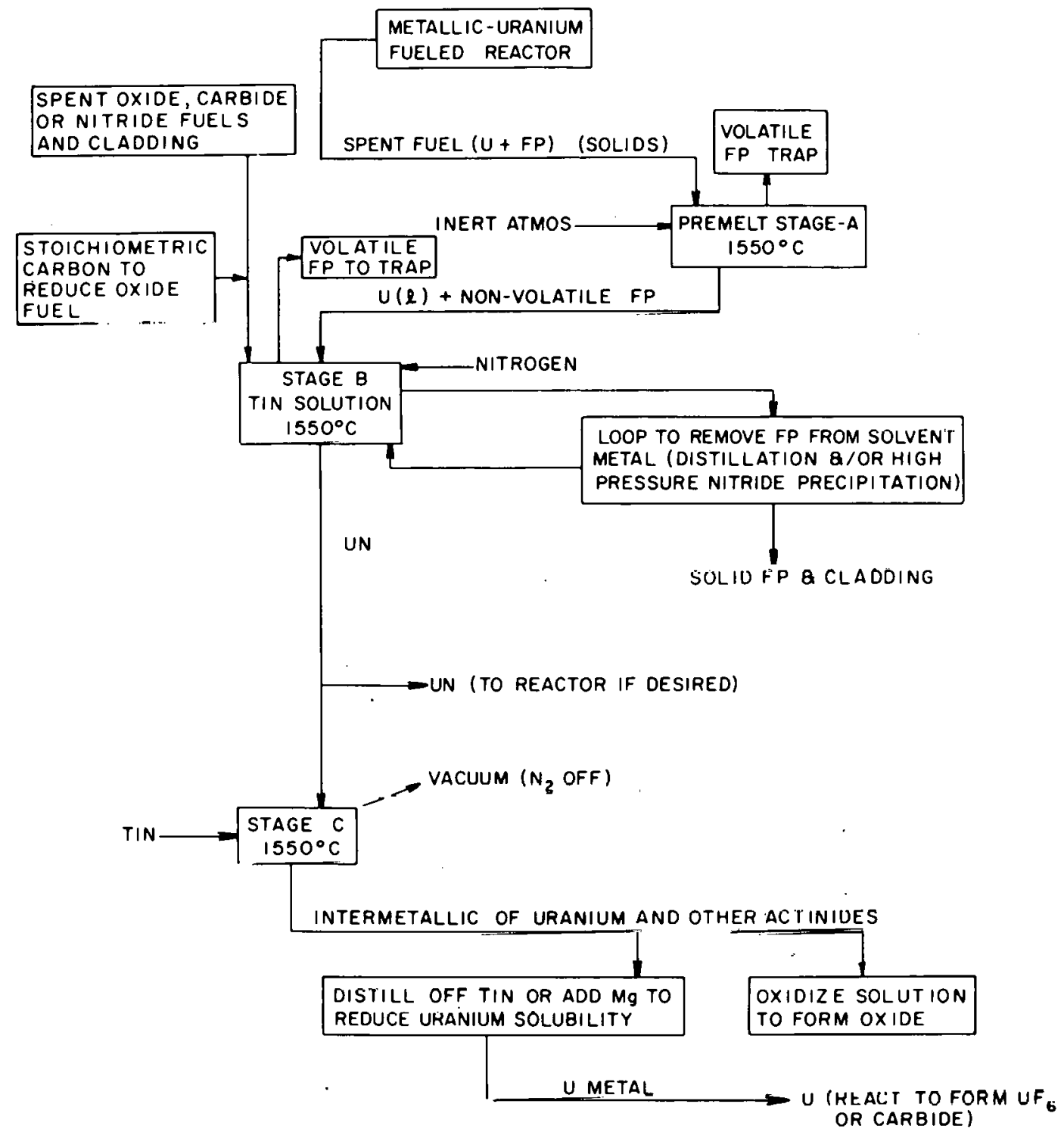

Figure 10. Tin-nitride process for spent fuel reproccosing. 


\section{Tin-Nitride Process}

1. Cost of production of $1 \mathrm{~kg}$ (300 MT/year)

2. Estimated Capital Cost

3. Separation factor for fission products Decontamination Factor: $\simeq 10^{3}$

4. Fission product waste form:

5. Waste material produced per $\mathrm{kg}$ fuel reprocessed:

6. Waste radiation level:

7. Fuel type accommodated:

8. Fuel Cooling requirements:

9. Breeder Fuel Capability:

10. Batch or continuous:

11. Handling of cladding material:

12. Form of reprocessed material:

13. Plutonium handling:

14. Handling of Radioactive gases:

15. Throughput/process inventory:

16. Maximum credible accident:
$\$ 15.47$

$\$ 12,382,500$

Gaseous and solidified tin ingot containing the f.p.

$\simeq 0.2 \mathrm{~kg}$ solidified in containing $f . p$.

Metallic, oxide, carbide, uranium thorium, plutonium

None

Yes for liquid metal reactor, if the liquid metal used is suitable for the process

Batch

Head-End treatment thought to be necessary. However, it might be possible to dissolve both fuel \& cladding \& separate them by sink float means.

UN

Not selective1.y separated

Can be collected during melting

Release of radioactive gases into atmosphere. Liquidation will solidify, containing within it all radioactive material 


\section{Tin-Nitride Process (Continued)}

17. Advantages:

18. Disadvantages:
(1) No cooling requirements, Sn resistant to radiation damage

(2) Rapid reprocessing

(3) Economical, compact equipment

(4) No liquid wastes

(5) Possibility of eliminating Head-end treatment

(1) Low decontamination factor

(2) Remote refabrication required

\section{Operating Costs}

1. Annual Plant Cost

2. Sn consumption ( $4 \%$ loss per cycle) $108,000 \mathrm{~kg}$ at $\$ 7.70 / \mathrm{kg}$

3. Utilities ( $25 \%$ of 1 )

4. Personnel 40 at $\$ 20,000$ p.a.

5. Fringe Benefits ( $25 \%$ of 4 )

6. Maintenance ( $1 \%$ of Total Capital Costs)

7. Insurance ( $5 \%$ of 1$)$

8. Cuntingencles (20\%)

Total Operating Costs

Cost of Reprocessing per kg fuel

$$
\begin{array}{r}
1,471,046 \\
831,600 \\
367,762 \\
800,000 \\
200,000 \\
123,825 \\
73,552 \\
\hline 3,867,785 \\
773,557 \\
\hline 4,641,342 \\
\hline \$ 15.47
\end{array}
$$


1. Process Equipment

$2,850,000$

2. Installation (40\%)

$1,140,000$

3. Instrumentation (10\%)

285,000

4. Buildings $25,000 \mathrm{ft}^{2}$ a $\$ 30 / \mathrm{ft}^{2}$

750,000

5. Waste Disposal Facilities

$2,000,000$

6. Services, Stores, and Yards

$1,000,000$

7. Laboratory and Administrative Facilities

$1,500,000$

$\overline{9,525,000}$

8. Engineering (10\%)

952,500

9. Contingencies (20\%)

$1,905,000$

Total Capital Costs

$12,382,500$

Annual Plant Cost

$1,471,046$

Process Equipment

1. 7 Ton Furnace including support equipment and shielding

$1,500,000$

2. 4 Ton Furnace for Sn recycle (at $75 \%$ of 1)

$1,125,000$

3. Sn distillation and condensation 225,000 equipment $(15 \%$ of 1$)$ 
THIS PAGE

\section{WAS INTENTIONALLY LEFT BLANK}


APPENDIX J: PUREX PROCESS (13)

$-89-$ 


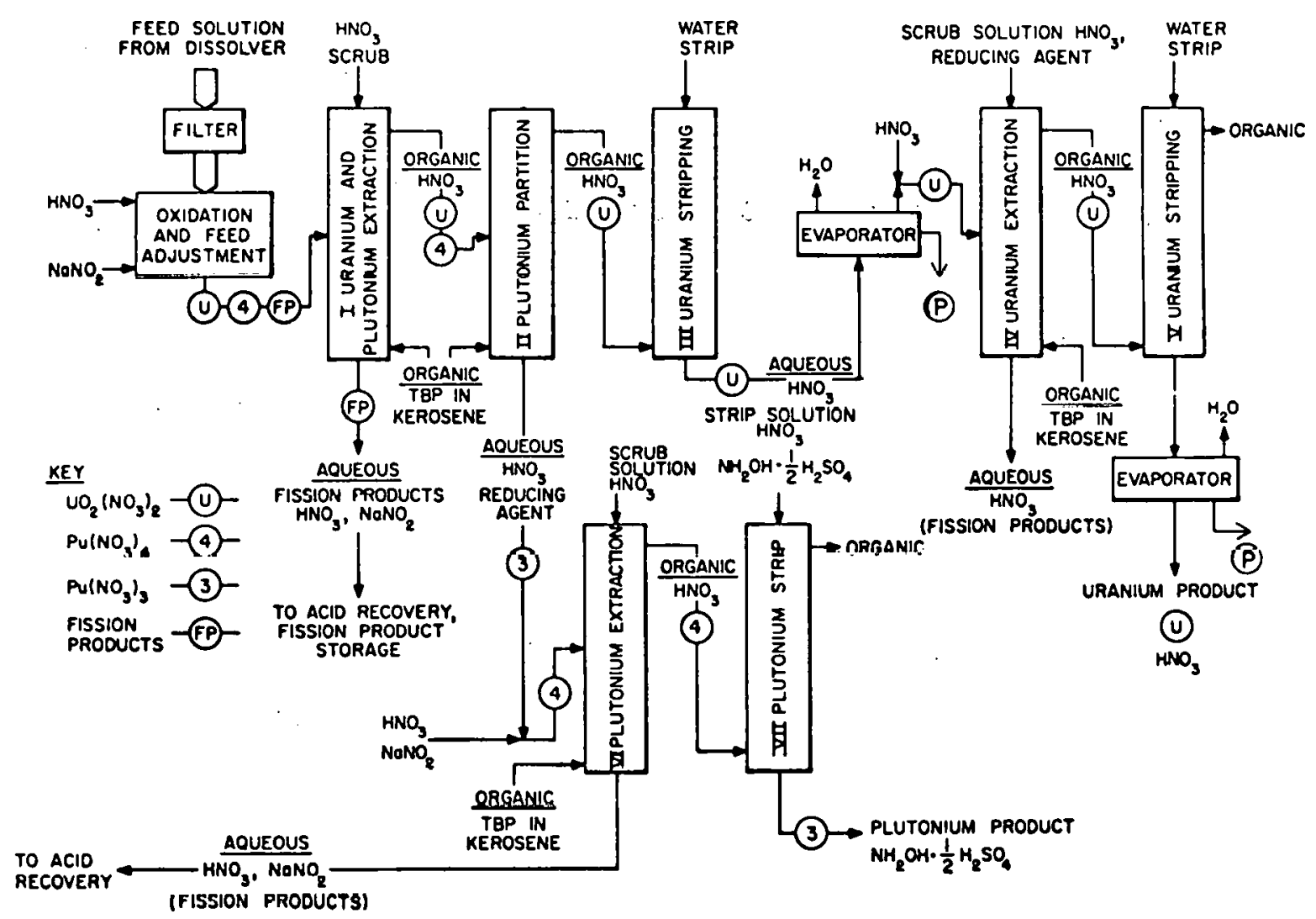

T1gure 11. Flow cliart ul purex process for treatment of low enriched uranium fuel. 
1. Cost of production of $1 \mathrm{~kg}$ ( $300 \mathrm{MT} /$ year)

2. Estimated Capital Cost

3. Separation Factor for fission products

Decontamination Factor: $10^{6} \simeq 10^{8}$

4. Fission Product Waste Form:

5. Waste material produced $/ \mathrm{kg}$ fuel reprocessed:

Warm and cold Waste $\simeq 1 \mathrm{~m}^{\mathrm{s}}$ (264 gal)

(Data from Eurochemic Plant):

Hot Waste: $0.8 \simeq 1.6 \mathrm{gal}$

Raffinate Column: $0.12 \mathrm{gal}$.

6. Waste Radiation level

Warm and Cold Waste: $<10^{2} \mathrm{Ci} / \mathrm{m}^{3}$
Hot Waste:

Raffinate Column

$$
50 \simeq 100 \mathrm{Ci} / \mathrm{m}_{3}^{3}
$$$$
7 \times 10^{5} \mathrm{Ci} / \mathrm{m}^{3}
$$

7. Fuel type accomnodated:

8. Fuel Cooling Requirements:

9. Breeder fuel capability:

10. Batch or continuous:

11. Handling of cladding material:

12. Form of reprocessed material:
$\$ 64.12$

$\$ 32,974,174$

Large Volume of liquid

$\mathrm{U}, \mathrm{Pu}, \mathrm{Th}$. Metallic and oxides; should be dissolvable in $\mathrm{HNO}_{3}$

Required Minimum 100 days, otherwise reagents suffer radiation damage

Possibly for Aqueous Homogenous Reactors. Necessary to pre-treat fuel to make it suitable for solvent extraction. Not suitable for Molten Salt or Liquid metal Reactors.

Continuous

Head-end treatment required

UNH 
13. Plutonium Handling:

14. Handling of Radioactive gases:

15. Throughput/process inventory:

16. Maximum credible accident:

17. Advallages:

18. Disadvantages:
$\mathrm{Pu}$ separated in 2nd Plutonium cycle, End-product is $\mathrm{Pu} \mathrm{O}_{2}$

Depends on Head-end Treatment

In case of $\mathrm{HNO}_{3}$ dissolution the reaction gases are:

$$
\begin{array}{ll}
\text { NO } & 4.05 \mathrm{ft}^{3} / \mathrm{kg} \\
\mathrm{NO}_{2} \mathrm{~N}_{2} \mathrm{O}_{4} & 2.95 \mathrm{ft}^{3} / \mathrm{kg} \\
\mathrm{N}_{2} \mathrm{CO}_{2} & 0.12 \\
\mathrm{~N}_{2} \mathrm{CO}_{2} & 0.12 \\
\mathrm{CO} \mathrm{H}_{2} & 0.12
\end{array}
$$

See Reagent consumption list

Spill of radioactive solutions which could seep down to subterranean water tables resulting larger scale contamination.

(1) Good deconcaminacion

(2) Suitable for centralized servicing of severl reactors

(1) Fuel precooling required

(2) Large volumes of liquid wates

(3) Large facilities, and therefore high capital costs. 


\section{Operating Costs}

1. Annual Plant Cost

$3,917,345$

2. Reagent Cost

$5,607,900$

3. Utilities ( $25 \%$ of 1$)$

979,336

4. Personnel 200 at $\$ 20,000$ p.à.

$4,000,000$

5. Fringe Benefits (at $25 \%$ of 4 )

$1,000,000$

6. Maintenance ( $1 \%$ of Total Capital Costs)

329,741

7. Insurance ( $5 \%$ of 1$)$

195,867

$\overline{16,030,189}$

8. Contingencies

$3,206,038$

Tota1 Operating Costs

$\overline{19,236,227}$

Cost of Reprocessing per $\mathrm{kg}$ fuel

$\$ 64.12$ 
1. Chemical Make-up and Storage

500,000

2. Process Equipment

$6,909,883$

3. Installation and Overhead. (40\%)

$2,763,933$

4. Instrumentation (10\%)

690,983

5. Buildings

$8,000,000$

6.: Liquid and Waste Disposal Facilities

$4,000,000$

7.: Services, Stores and Yards

$1,000,000$

8.. Laboratory and Administrative Facilities

$1,500,000$

$\overline{25,364,749}$

9. Engineering (10\%)

$2,536,475$

10. Contingencies (20\%)

$5,072,950$

Total Capital Costs

$32,974,174$

Annual Plant Costs

$3,917,345$

Process Equipment

1. Dissolution

325,000

2. Solvent Extraction Equipment

$3,490,490$

3. Evaporators

651,000

4. Pipes, valves and fittings ( $50 \%$ of 2 )

$1,745,245$

5. Electrical and special equipment ( $20 \%$ of 2 ) 698,098 Total Procese Equipment 
Reagent Consumption Per Day

1. $\mathrm{HNO}_{3}$

2. $\mathrm{TBP}$

3. Kerosene

4. Other reagents

Total Reagent Costs
$137 \mathrm{~kg} @ \$ 67.28 / \mathrm{kg}$

$360 \mathrm{~kg} @ \$ 12.85 / \mathrm{kg}$

228 gal @ \$ 13.10/gal

9,215

4,632

2,993

1,853

18,693 
THIS PAGE

\section{WAS INTENTIONALLY LEFT BLANK}


APPENDIX K: REDOX PROCESS (14) 


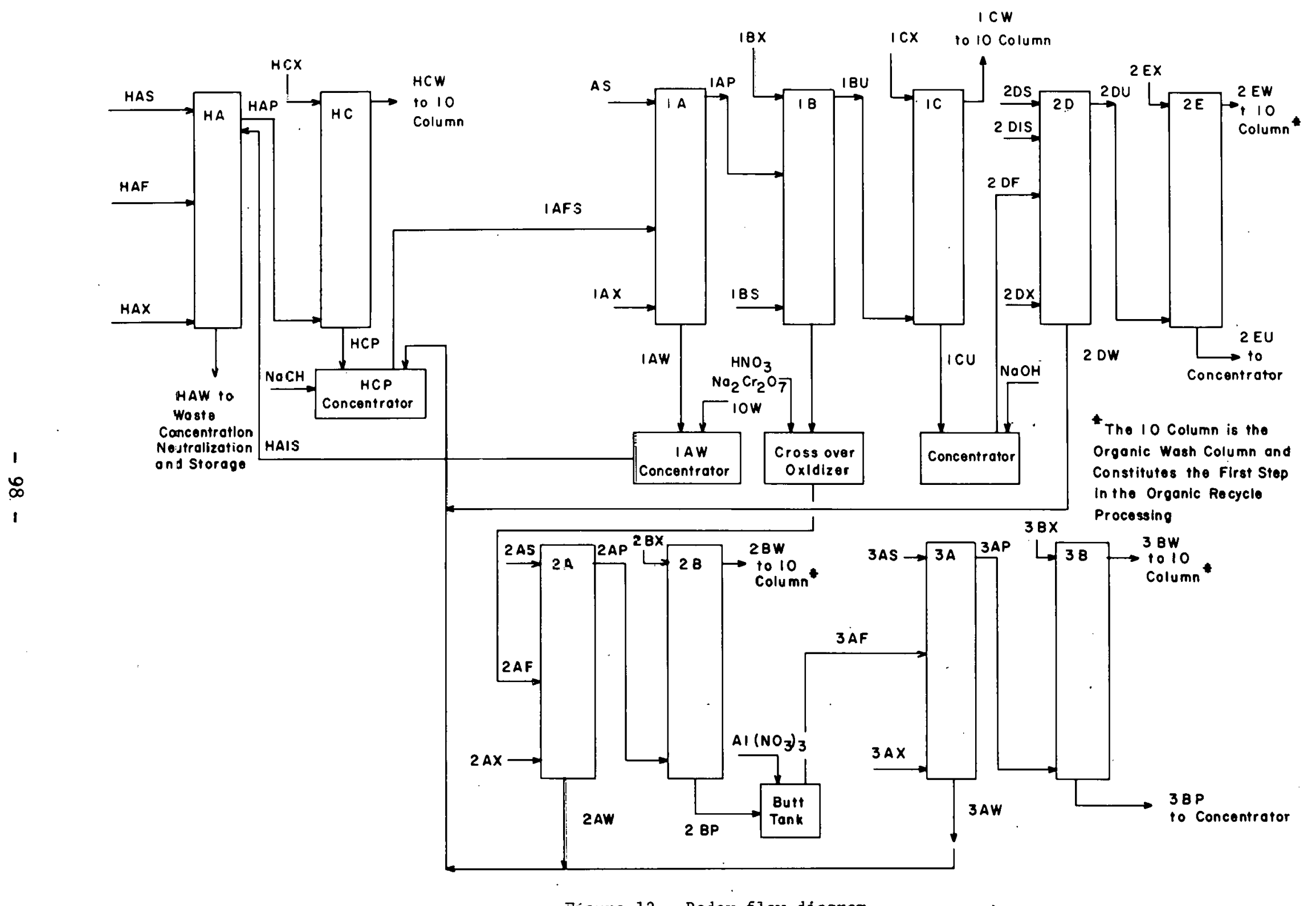

Figure 12. Redox flow diagram. 
1. Cost of production of $1 \mathrm{~kg}$ (300 MT/year)

2. Estimated Capital Costs..

3. Separation Factor for Fission products

Decontamination Factor: $10^{6} \simeq 10^{8}$

4. Fission Product Waste Form:

5. Waste material produced $/ \mathrm{kg}$ fuel reprocessed:

6. Waste radiation level:

7. Fuel type accommodated

8. Fuel cooling requirements:

9. Breeder Fuel Capability:

10. Batch or continuous:

11. Handling of cladding material:

12. Form of reprocessed material:

13. Plutonium, handling:

14. Handling of radioactive gases:
$\$ 82,92$

$\$ 43,869,227$

Liquid

More than Purex

Warm and Cold Waste $\sim<$ Purex

Hot Waste $\sim<$ Purex

Raffinate Column $\quad \sim<$ Purex

$\mathrm{U}, \mathrm{Pu}, \mathrm{Th}$, metallic and oxides should be dissolved in $\mathrm{HNO}_{3}$

Approximately 100 days (sufficient for radioactive decay (U-237)

Possibly for Aqueous Homogenous Reactors necessary to pre-treat fuel to make it suitable for solvent extraction.

\section{Continuous}

Head-end Treatment required

Solution $\mathrm{UO}_{2}\left(\mathrm{nO}_{3}\right)_{2} \mathrm{Pu}$ (IV) in aqueous solution?

About $99 \%$ of the $P u$ is recovered in the 3 rd $\mathrm{Pu}$ cycle, in the form of $\mathrm{Pu}^{\prime}$ (IV). in aqueous solution. This can then be further processed to desired chemical form.

Depends on Head-end Treatment. If $\mathrm{HNO}_{3}$ dissolution is done ref purex. ${ }^{3}$ In addition, $\mathrm{RuO}_{4}$ is volatilized during bolling prior to centrifiguration. . 
15. Throughput/process inventory:

16. Maximum credible accident:

17. Advantages:

18. Disadvantages:
See chemicals and Reagents Consumption list.

Spill of radioactive solutions which could seep down to subterranean water tables, resulting in large scale contamination.

(1) Good decontamination

(2) Suitable for large scale operation; benefits from economy of scale

(1) Fuel precooling required

(2) Large volumes of liquid wastes

(3) Large plant facilities, and therefore high capital. costs

(4) Hexone - $\mathrm{HnO}_{3}$ dangerous mixture, possible explosion.

\section{Operating Costs}

1. Annual Plant Cost

$5,211,682$

2 year deferment followed by 20 year straight

line depreciation at $8 \%$ interest per annum

2. Chemicals and Reagents

$8,256,000$

3. Utilities ( $25 \%$ of 1$)$

$1,561,920$

4. Personnel 200 at $\$ 20,000$ p.a.

$4,000,000$

5. Fringe Benefits (at $25 \%$ of 4 )

$1,000,000$

6. Maintenance ( $1 \%$ of Total Capital Cinst)

138,692

7. Insurance $(5 \%$ of 1$)$

260,584

$20,728,878$

8. Contingencies (at 20\%)

$4,145,776$

Total Operating Cost

$24,874,654$

Cost of Reprocessing per $\mathrm{kg}$ fuel

$\$ 82.92$ 
1. Chemical Make-up and Storage

500,000

2. Processing Equipment

$9,303,366$

3. Installation and Overheads (at 40\%)

$3,721,346$

4. Instrumentation (at $10 \%$ of 2 )

930,336

5. Buildings

$11,190,511$

6. Liquid and Waste Disposal Tanks

$5,600,000$

7. Services, Stores, and Yards

$1,000,000$

8. Laboratory and Administrative Facilities

$1,500,000$

$\overline{33,745,559}$

9. Engineering (10\%)

$3,374,556$

10. Contingencies (20\%)

$6,749,112$

Total Capital Costs

$4 \longdiv { 4 3 , 8 6 9 , 2 2 7 }$

Annual Plant Cost

$5,211,682$

Process Equipment

1. Dissolution

325,000

2. Processing Equipment (Purex $x$ 1.4)

$4,886,686$

3. Evaporators

651,000

4. Pipes, Valves and Fittings ( $50 \%$ of 2 )

$2,443,343$

5. Electrical and Special Equipment (20\% of 2)

997,337

Total Process Equipment

$9,303,366$ 


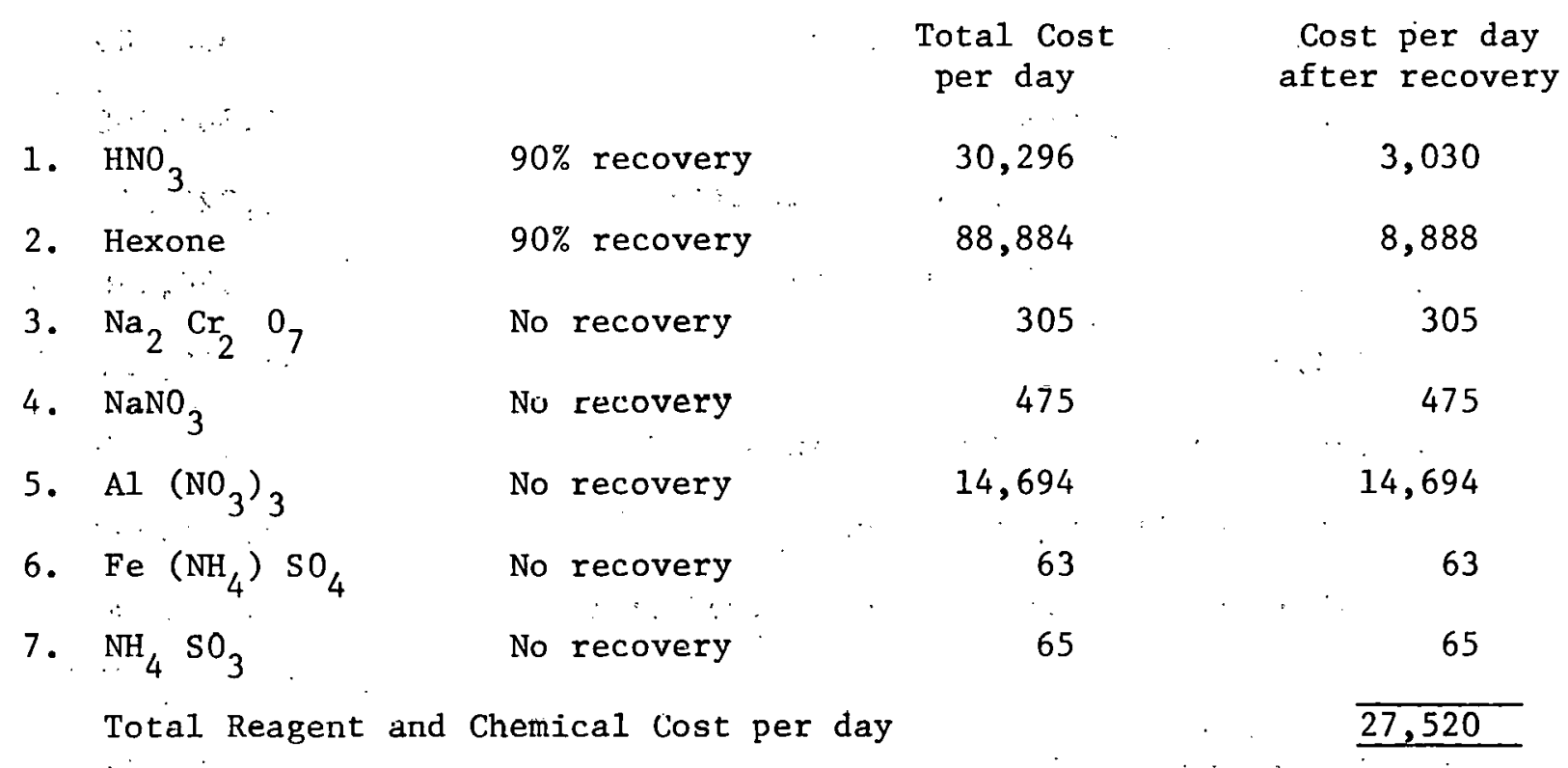


APPENDIX L: SALT TRANSPORT PROCESS (15) 


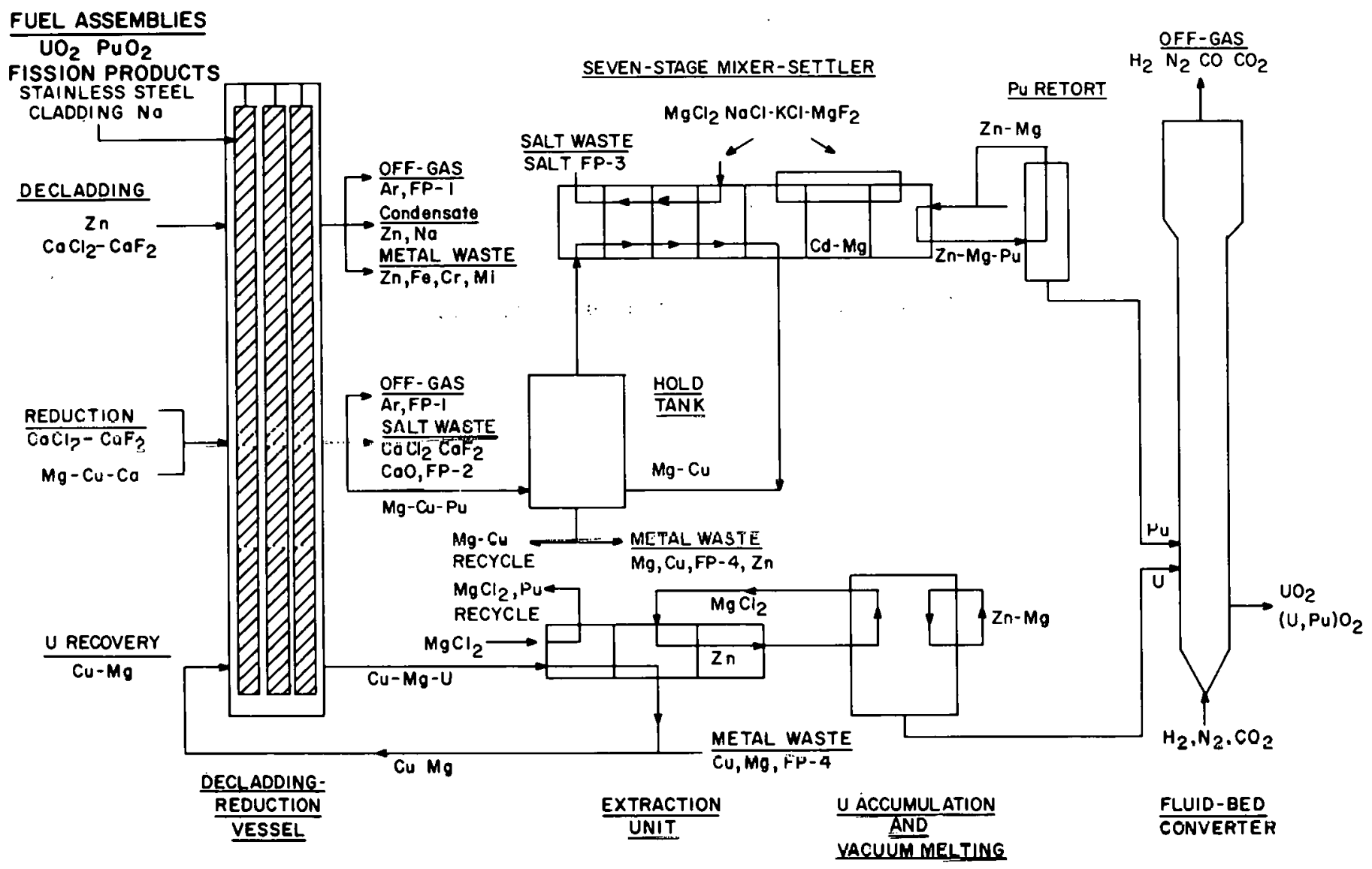

KEYTO FISSION PRODUCTS

$F P-1 K_{r}, X_{\theta}, 3, H,(1)$

FP.2 Rb, Cs, Sr, Bo, Sm

FP-3 Y, RARE EARTHS

FP-4 Zr, Nb, Mo, TC, Ru, Rh, Pd

Figure 13. Salt transport process. 
1. Cost of production of $1 \mathrm{~kg}$ ( $300 \mathrm{MT} /$ year)

2. Estimated Capital Cost

3. Separation Factor for fission products Decontamination Factor: $<10^{6}$

4. Fission Product Waste Forms:

5. Waste material produced per $\mathrm{kg}$ fuel reprocessed:

6. Waste radiation level:

7. Fuel Type Accommodated:

8. Fue1 Cooling Requirements:

9. Breeder fuel capacity:

10. Batch or continuous

11. Handling of cladding material:

12. Form of Reprocessed Material:

13. Plutonium Handling:

14. Handling of radioactive gases:

15. Throughput/process inventory:

16. Maximum credible accident:
$\$ 21.16$

$\$ 12,438,400$

Contalned in waste salt or metal: solids at room temperature. Gaseous wastes too - $\mathrm{Ar}, \mathrm{Kr}, \mathrm{Xe}, \mathrm{I}$

No data

Metallic, oxide, carbide fuels

30 days

Yes, LMFBR and Molten salt B.R.

Decladding oxidation, reduction: Batch; extraction, U-Accumulation: Continuous

Zinc dissolution

$\mathrm{UO}_{2}, \mathrm{PuO}_{2}$

$\mathrm{Pu}$ is separated, and converted to $\mathrm{PuO}_{2}$ in Fluid Bed Convertor

Collect in inert gas and store

$910 \mathrm{~kg} \mathrm{Zn/day;} 277 \mathrm{~kg} \mathrm{Ca} /$ day $376 \mathrm{~kg} \mathrm{Cn} /$ day; $181 \mathrm{~kg} \mathrm{Mg} /$ day

Release of radfoactive gases into the atmosphere. High temperature molten salt and liquid metal containing fission produced will solidify on cooling. 
17. Advantages

(1) Versatility

(2) Short Cooling period

(3) Zinc Decladding - no separate Head-End treatment required.

(4) Solid Wastes.

18. Disadvantages

(1) Possible contamination by $\mathrm{Cu}, \mathrm{Mg}$ or $\mathrm{Cd}$.

(2) Several different reagents used; 6 salts and 4 metals. 
1. Annual Plant Cost

2 year deferment followed by 20 year

$1,477,687$ straight line depreciation at $8 \%$

interest p.a.

2. Zinc Consumption (at $8 \%$ loss per cycle)

210,395 $273,240 \mathrm{~kg}$ at $\$ 0.77^{\circ}$ per $\mathrm{kg}$

3. Ca consumption ( $277 \mathrm{~kg} /$ day $\mathrm{x} \$ 2.92 / \mathrm{kg} \times 3.00$ 243,000 days )

4. $\mathrm{Cu}$ consumption (376 kg/day $\mathrm{x} \$ 1.63 / \mathrm{kg} \cdot \mathrm{x} \cdot 300$ 55,080 days)

5. Mg consumption (181 kg/day $\times \$ 2.06 / \mathrm{kg} \times 300$ days)

33,660

6. Salt consumption $\begin{array}{ll}\mathrm{CaCl}_{2} & \begin{array}{c}(111 \mathrm{~kg} / \text { day } \times \$ 2.31 / \mathrm{kg} \times 300 \\ \text { days })\end{array} \\ \mathrm{CaCl}_{2} & (19.5 \mathrm{~kg} / \text { day } \times \$ 6.86 / \mathrm{kg} \times 300\end{array}$

703,200

7. Utilities (25\% of 1$)$

369,422

8. Personnel 80 at $\$ 20,000$ p.a.

$1,600,000$

9. Fringe Benefits (at $25 \%$ of 8 )

400,000

10. Maintenance ( $1 \%$ of Total Capital Cost)

124,384

11. Insurance ( $5 \%$ of 1 )

$\therefore \quad 73,884$

$55,290,712$

12. Contingencies (at 20\%)

$1,058,142$

Total Operating Cost

$6,348,854$

Cost of reprocessing per $\mathrm{kg}$ fuel

$\$ 21.16$ 
1. Processing Equipment

$4,280,000$

2. Installation and Overheads (at 40\%)

$1,712,000$

3. Instrumentation (at $10 \%$ of 1 )

428,000

4. Buildings $50,000 \mathrm{ft}^{2}$ a $\$ 30 / \mathrm{ft} \mathrm{t}^{2}$

$1,500,000$

5. Services, Stores and Yards

$1,000,000$

6. Laboratory and Administrative Facilities

$1,500,000$

7. Waste Disposal Facilities

$3,000,000$

$9,568,000$

8. Engineering (at 10\%)

$956,8 \cap n$

9. Contingencies (at 20\%)

$1,913,600$

Total Capital Costs

$\overline{12,438,400}$

Annual Plant Cost

$1,477,687$

\section{Process Equipment}

1. 7 Ton f'urnace including support equipment and shielding

$1,500,000$

2. Hold Tank

10,000

3. 7-stage mixer settler

$1,000,000$

4. $\mathrm{Pu}$ Retort

70,000

5. U Extraction Unit

500,000

6. Fluid Bed Convertor

500,000

7. U accumulation and Vacuum Melting

700,000

Total Process Equipment

$4,280,000$ 
APPENDIX M: THOREX PROCESS (16)

- 109 - 


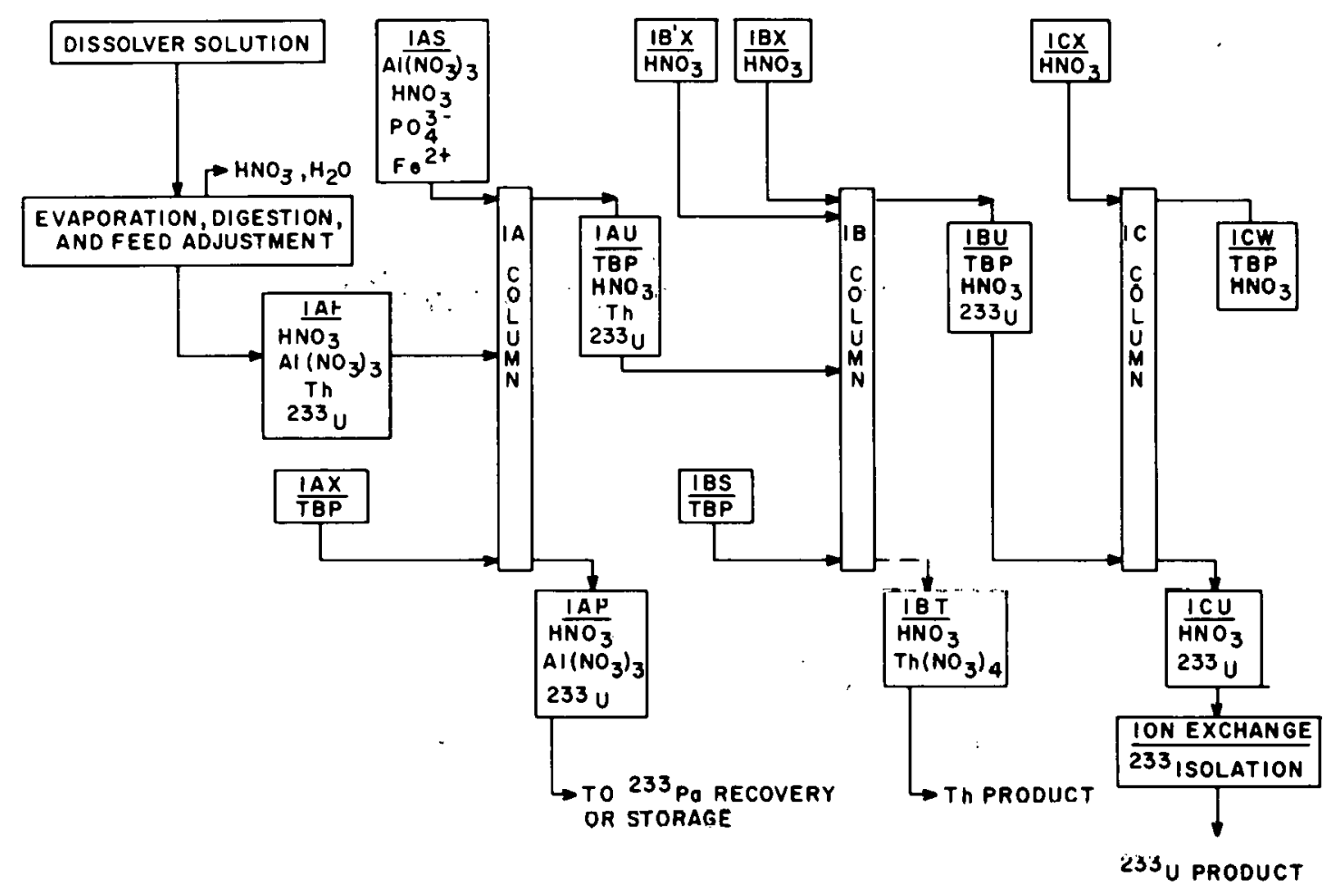

Figure 14. Thorex process flowsheet. 
1. Cost of production of $1 \mathrm{~kg}$ ( $300 \mathrm{MT} /$ year)

2. Estimated Capital Cost

3. Separation Factor for fission products:

Decontamination Factor: $10^{6} \simeq 10^{8}$

4. Fission product waste form:

5. Waste material produced per $\mathrm{kg}$ fuel reprocessed:

6. Waste radiation level:

7. Fuel type accommodated:

8. Fuel cooling requirements:

9. Breeder Fuel Capability:

10. Batch or continuous:

11. Handling of cladding materials:

12. Form of reprocessed material:

13. Plutoni,um handling:

14. Handling of radioactive gases:

15. Throughput/process inventory:

16. Maximum credible accidents:

17. Advantages:

18. Disadvantages:
$\$ 60.49$

$\$ 20,898,496$

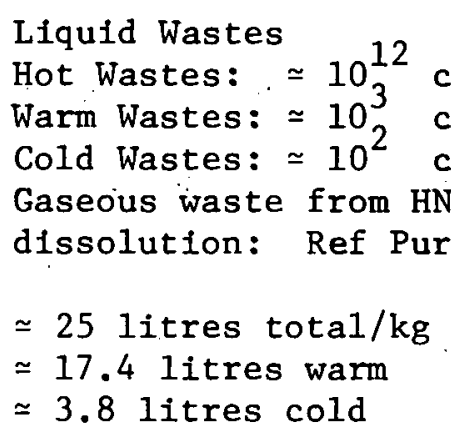

See 4 above

Thorium; Thorex is Purex equivalent for Thorium

Minimum 40 days

Not Molten Salt or liquid metal reactor fuels

Continuous

Head-End Treatment required

Liquid; Thorium in aqueous nitrate solution

None

Collected and Stored

See Reagents List

As in Purex

(1) Good separation factor

(1) Precooling required

(2) Liquid wastes

(3) Economic Disadvantages 
1. Annual Plant Costs

2 year deferment followed by 20

year straight line depreciation

at $8 \%$ interest p.a.

2. Chemicals and Reagents

$6,684,900$

3. Utilities

620,687

4. Personnel 200 C 20,000 p.a.

$4,000,000$

5. Fringe Benefits (at $25 \%$ of 4 )

$1,000,000$

6. Maintenance ( $1 \%$ of Total Capital Cost)

208,985

7. Insurance ( $5 \%$ of 1 )

124,137

$\overline{15,121,459}$

8. Contingencies (at 20\%)

$3,024,292$

Total Annual Operating Cost

$\overline{18,145,751}$

Cost of Reprocessing per kg fuel

$\$ 60.49$ 
1. Chemical Make-up and Storage 500,000

2. Processing Equipment $3,341,540$

3. Installation and Overheads ( $40 \%$ of 2 ) $1,336, \dot{6} 16$

4. Instrumentation (at $10 \%$ of 2 ) 334,154

5. Buildings (2.29 x Processing Equipment) $4,063,456$

6. Services, Yards and Stores $1,000,000$

7. Laboratory and Administrative Facilities $1,500,000$

8. Liquid and Waste Disposal Tanks $4,000,000$ $\overline{16,075,766}$

9. Engineering (at 10\%) $1,607,577$

10. Contingencies (at 20\%)

$3,215,153$

Total Plant Cost

$\overline{20,898,496}$

Annual Plant Cost

$2,482,750$

\section{Process Equipment}

1. Dissolution

325,000

2. Processing Equipment Purex $\times\left(\frac{34}{105}\right)$

0.6

3. Pipes, Valves and Fittings ( $50 \%$ of 2 )

$1,774,435$

887,218

4. Electrical and Special Equipment ( $20 \%$ of 3 ) 354,887 Total Process Equipment

$\overline{3,341,540}$ 
Reagent Cost (Per Day)

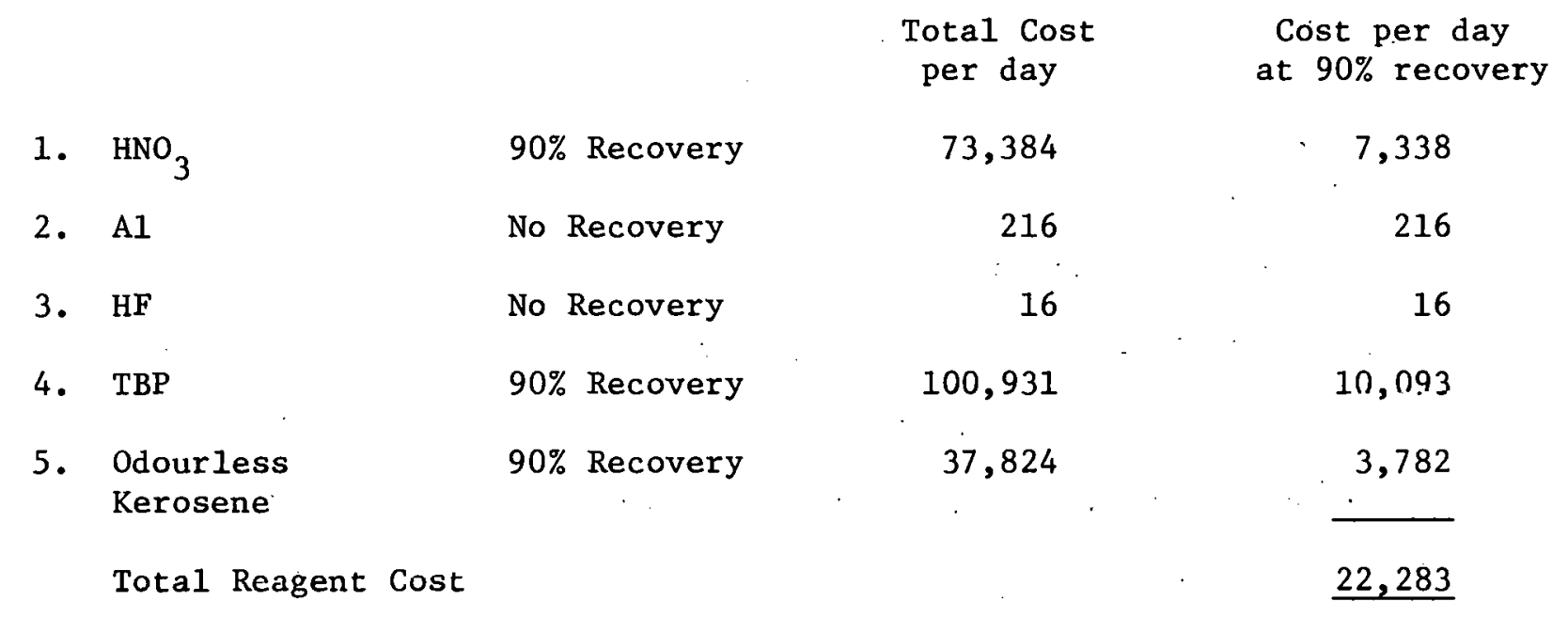


APPENDIX N: ZINCAL PROCESS (17) 


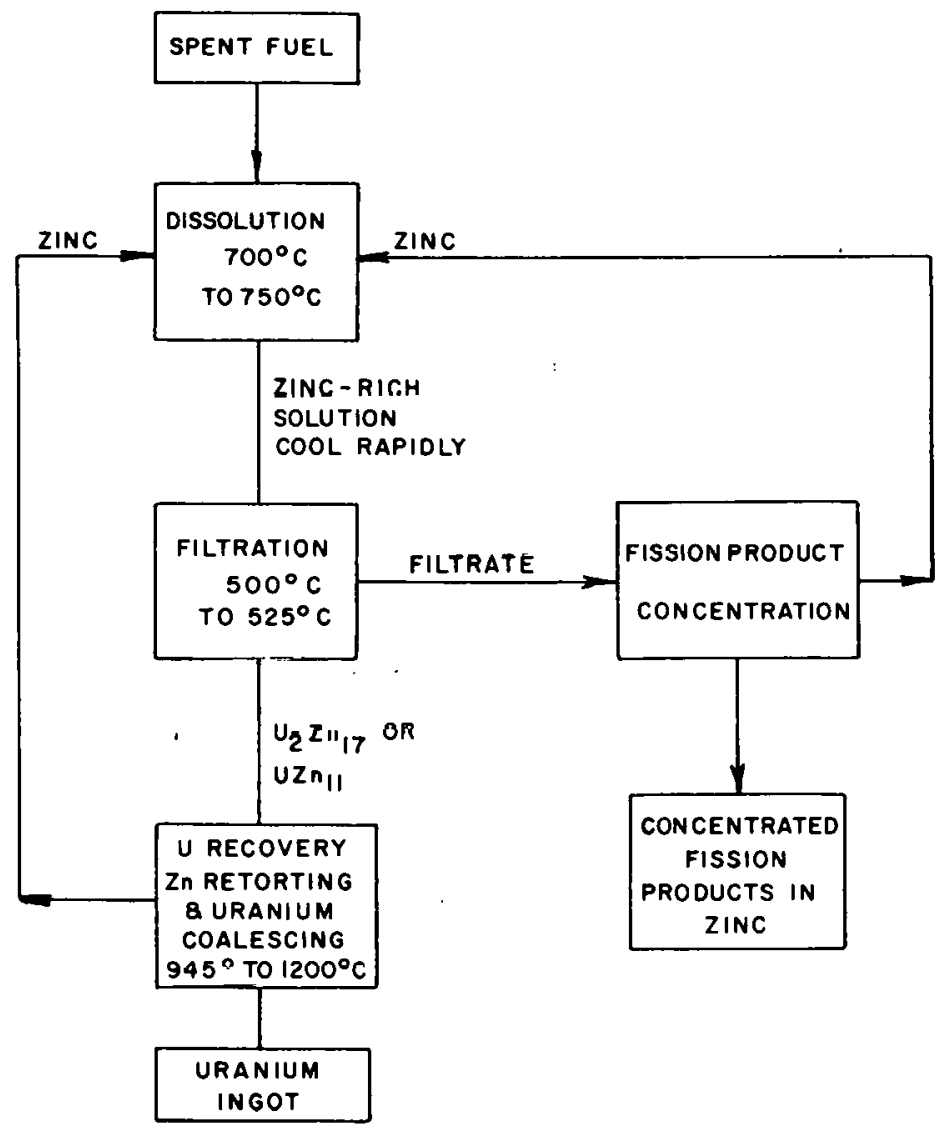

Figure 15. Zincal (pyrozinc) reprocessing flow diagram. 


\section{Zincal Process}

1. Cost of production of $1 \mathrm{~kg}$ (300 MT/year

2. Estimated Cost

3. Separation Factor for Fission Products:

Decontamination Factor:

4. Fission Product Waste For:

5. Waste material produced per $\mathrm{kg}$ : fuel reprocessed

6. Waste radiation level:

7. Fuel type accommodated:

8. Fuel Cooling Requirements:

9. Breeder Fuel Capability:

10. Batch

11. Handling of cladding material:

12. Form of reprocessed material:

13. Plutonium handling:

14. Handling of radioactive gases:

15. Throughput/process inventory:

16. Maximum credible accident:

17. Advantages:
$\$ 16.82$

$\$ 15,648,750$

$10^{3}$

Concentrated in solid Zinc; gas.

$\simeq 0.4 \mathrm{~kg} \mathrm{Zn}$

Metallic and Oxide U

UC possible after conversion to $\mathrm{UO}_{2}$

None

Liquid metal, if it is metallic uranium

Head-End treatment least complicated; however, possible to dissolve $\mathrm{Zr}$ cladding material simultaneously

Metallic uranium ingot

No selective separation; $\mathrm{Pu}$ probably comes out with the $\mathrm{U}_{2}{ }^{\mathrm{Zn}} 17$

Collect and store

Release of radioactive gases to the atmosphere

(1) Rapid reprocessing - no precooling requirements

(2) Economical; compact equipment

(3) No liquid wastes 


\section{Zincal Process (Continued)}

18. Disadvantages:

(1) $\mathrm{U}_{2} \mathrm{Zn}_{17}$ alloy very large molecules-easy to be contaminated

(2) Low decontamination

\section{Operating Costs}

1. Annual Plant Cost

2. Zn consumption (at $8 \%$ loss per cycle) $775,224 \mathrm{~kg}$ at $\$ 0.81 / \mathrm{kg}$

3. Utilities ( $25 \%$ of ' 1 )

4. Personnel 40 at $\$ 20,000$ p.a

5. Fringe Benefits (25\% of 4 )

6. Maintenance ( $1 \%$ of Total Capital costs)

7. Insurance ( $5 \%$ of 1 )

8. Contingencies (20\%)

Total Operating Costs

Cost of Reprocessing per kg fuel

$$
\begin{array}{r}
1,859,077 \\
631,032 \\
464,769 \\
800,000 \\
200,000 \\
156,488 \\
y 2,954 \\
\frac{4,2114,320}{8110,864} \\
\frac{5,045,184}{\$ \$ 16.82}
\end{array}
$$


1. Process Equipment

2. Installation and Overheads ( $40 \%$ of 1 )

3. Instrumentation ( $10 \%$ of 1 )

4. Buildings $20,000 \mathrm{ft}^{2}$ \& $\$ 30 / \mathrm{ft}^{2}$

5. Waste Disposal Facilities

6. Services, Stores and Yards

7. Laboratory and Administrative Facilities

8. Engineering ( $10 \%)$

9. Contingencies (20\%)

Total Capital Costs

Annual Plant Cost
$4,625,000$

$1,850,000$

462,500

600,000

$2,000,000$

$1,000,000$

$1,500,000$

$\overline{12,037,500}$

$1,203,750$

$2,407,500$

$\overline{15,648,750}$

$1,859,750$

\section{Process Equipment}

1. $2 \times 7$ Ton Furnaces including support equipment and shielding

2. Filtration Equipment

3. EP concentration and $\mathrm{Zn}$ Recycle

4. U Recovery and Zn Retort Distillation

Total Process Equipment
500,000

$1,125,000$

500,000

$2,500,000$

$4,625,000$ 